\title{
El tesoro de monedas árabes de Carmona y una rectificación de A. Vives Escudero ${ }^{1}$
}

\author{
Alberto J. CANTO GARCÍA (U.A.M.) \\ Fátima MARTÍN ESCUDERO (U.C.M.)
}

\section{Resumen}

Análisis del tesoro de monedas árabes de Carmona (Sevilla) a través de la documentación conservada. Se incluye una corrección de lectura de una moneda realizada por Antonio Vives Escudero.

Palabras clave: Al-Andalus, numismática islámica, hallazgos, revisión de fechas.

\section{Summary}

An analysis of the silver coins hoard from treasure Carmona (Seville) is made through the conserved documentation. A correction of a coin date by Antonio Vives Escudero.

Keywords: Al-Andalus, islamic numismatic, hoards, date correction.

Lo habitual en un estudio de un hallazgo monetario es realizarlo sobre el análisis directo de las piezas y complementarlo, en casos excepcionales, con la documentación escrita generada a raíz de su descubrimiento (Canto y Martín Escudero, 2000: 27-40; Martín Escudero, 2003: 257-268; Canto, Martín, Vico, 2002). Menos habitual es llevar a cabo dicho estudio a través, tan sólo, de la documentación asociada al mismo, aunque en los últimos años, ante un despertar de los estudios historiográficos numismáticos, se han comenzado a analizar conjuntos de los que sólo se

1 Este trabajo se ha realizado dentro del proyecto "Materiales de Madinat al-Zahra: Producción y Circulación de Bienes en al-Andalus (REFERENCIA: HAR2009-10011 (subprograma HIST)" del Ministerio de Educación y Ciencia, bajo han localizado documentación escrita, bien porque el material principal, las monedas, se ha desperdigado entre diferentes colecciones públicas y privadas $^{2}$, bien porque estando en colecciones públicas, sea de difícil acceso.

Este es el caso del hallazgo monetario que vamos a analizar, el conocido como tesoro de Santa Clara o de Carmona.

Aparecido en julio de 1907, cerca de Carmona, en concreto a 8 kilómetros de la ciudad, junto al cortijo de Santa Clara y el río Corbones, de las

la dirección de E. Manzano.

2 Rodríguez, 2009: 149-159. Más ejemplos en Canto, Martín y Vico, 2002; Martín Escudero, 2011 o Canto y Martín Escudero, 2007: 75-80. 
circunstancias del hallazgo nada sabemos, sí de su composición, unos 200 dírhams, su cronología, del Califato omeya de Damasco, y su posterior dispersión. Todo ello gracias a la documentación escrita y gráfica conservada del mismo. Las piezas monetarias se distribuyeron en colecciones privadas de la época, algunas reconvertidas a públicas, como el Instituto Valencia de Don Juan ${ }^{3}$ y en una donación puntual a los Museo Británico y Arqueológico Nacional.

De dicho conjunto, si bien nunca se han publicado las imágenes de las monedas, si se ha hecho de referencias a la documentación vinculada al mismo. Así en 1907 el ilustre arabista Asín Palacios insertó una somera nota del descubrimiento en el número 4 de la revista Cultura Española en la que indica las 21 monedas adquiridas en un principio ${ }^{4}$ : "Durante este verano se ha descubierto un tesoro de monedas árabes de plata en un predio de Carmona cuya demarcación precisa no conocemos. El núcleo principal de este hallazgo fue adquirido por D. Juan Fernández..." (Asín, 1907: 971-972).

En 1956 Walker, al estudiar y publicar la colección de moneda árabe del Museo Británico, indica como procedencia de dos piezas, ceca Wasit, año 108H./726d.C. y al-Andalus, 129H./746d.C., el hallazgo de Carmona, regalo de J. de Osma (Walker, 1956: 195 n ${ }^{\circ} .555$ y 122 $\left.\mathrm{n}^{\circ} .294\right)$.

Hasta el año 1998 nada más se supo del mismo. Hasta que J. Maier, al analizar la documentación de Jorge Bonsor, halló, entre su correspondencia, referencias al mismo. A partir de dicho año varias han sido las publicaciones que han recogido de forma parcial información de dicho hallazgo ${ }^{5}$.

Ante el descubrimiento de más documentación vinculada al hallazgo de Carmona, nos proponemos tanto publicar dicho material como

3 Agradecemos al Instituto Valencia de Don Juan y en particular a Dña. Cristina Partearroyo el haber podido consultar la documentación relativa al hallazgo en dicha institución.

4 Véanse las monedas en la tabla primer envío del informe de Vives depositado en el IVDJ.

5 Maier, 1998: 79-93, n 243-245; Maier, 1999; Maier, 2004 78-84; Martín Escudero, 2005a; Martín Escudero, 2005b: recopilar y analizar el ya publicado, con el fin de obtener una visión más completa y definitiva del tesoro. Además de los comentarios que uno de los principales numismáticos de la época, Antonio Vives y Escudero, vertió sobre dicho conjunto y sus monedas.

Dicha documentación procede tanto del Archivo personal de Jorge Bonsor, depositado en el Archivo General de Andalucía, como de la correspondencia entre Juan Fernández López y Guillermo de Osma, depositada también en el Archivo General de Andalucía, legajo n ${ }^{\circ} 13$, y del archivo del Instituto Valencia de Don Juan, en el que encontraremos tanto el informe del conjunto, anónimo pero que podemos suponer realizó Vives y Escudero, ya que en algún momento del texto cita como suya la obra sobre las dinastías arábigoespañolas de 1893, como el listado de composición de los diferentes lotes que recibe Osma por parte de Fernández López y las fichas del monetario de la institución como de material gráfico, improntas de las propias monedas, en su mayoría elaboradas por Antonio Prieto y Vives ${ }^{6}$. Suponemos que en la citada institución se conservan parte de las monedas aparecidas en el hallazgo de Carmona, pero nos ha sido imposible poder acceder a las mismas. Hallamos también documentación relacionada en el Museo Arqueológico Nacional.

Entre la correspondencia podemos citar la mantenida entre Guillermo de Osma, célebre coleccionista y fundador del Instituto Valencia de Don Juan y Juan Fernández, erudito local, y de Jorge Bonsor, arqueólogo inglés asentado en la zona, con Archer M. Huntington, fundador de la Hispanic Society.

El extracto de la carta de Bonsor a Huntington, escrita desde Mairena del Alcor el 14 de octubre de 1907, dice así (Maier, 1999: carta $\mathrm{n}^{\mathrm{o}} 58$, p. 160):

1615-1623 y, como comentaremos más adelante, Grañeda, 2009: 771-797

6 Ibrahim, 2003: 313-324 y proyecto 06/0131/2002 de la Comunidad de Madrid, Estudio y clasificación del material gráfico numismático, de época andalusí, depositado en el Instituto Valencia de Don Juan de Madrid, director Alberto Canto García. 
"Tengo que mencionarle un hallazgo de monedas de plata árabes en el Cortijo de Santa Clara, cerca de Carmona, a corta distancia de otra granja llamada La Capilla, célebre por haberse descubierto en ella, hace unos años, monedas de oro visigóticas, en su mayor parte hoy en día en su colección. Las monedas árabes (de las cuales he podido recolectar 33), siento decirle que son todas del mismo tipo, del califa de Damasco AbdelMalik, 638 d.C.”.

Mayor número de cartas se intercambiaron Osma y Fernández al efecto, conservándose en el Archivo General de Andalucía (Legajo 13, página 27) (Maier, 2004):

\section{$\operatorname{Carta~}^{\circ} 1$}

El Ministro de Hacienda

Madrid, 2 de noviembre de 1907

\section{Sr. D. Juan Fernández López}

Mi estimado amigo:

Recibida su carta, ayer se dio cuenta de ella a los amigos aficionados, y todos agradecemos que logre V. por cuenta mia, y mediante su activa bondad, rescatar del olvido el mayor número posible de aquellas monedas.

Perdone V. que, ignorando que hubiese fallecido su hermano (q.s.g.h.) me dirigiera a él, avivando así con el recuerdo, el dolor de V.

Seguro afmo. amigo q.b.s.m.

Guillermo de Osma

\section{Carta $\mathbf{n}^{\circ} 2$}

El Ministro de Hacienda

Madrid, 3 de noviembre de 1907

\section{Sr. D. Juan Fernández López}

(...)

Vino a visitarme en nombre de Ud. y por indicación de nuestro común amigo, D. Lorenzo Domínguez Pascual, D. Eduardo Torralbo, y pudimos hablar del curioso hallazgo de monedas arábigas. Tenía para mí especial interés el hecho de encontrarse juntas, y en España, más monedas acuñadas en Andalucía, con otras acuñadas en Oriente, que les sirvieran de modelo: demostrándose así que en España circularon a una vez desde que tuve noticia del hallazgo, deseaba traer a mi pequeña colección algunas de aque- llas, y conocer, sobre todo, cuantos detalles den mejor a conocer las circunstancias del hallazgo mismo.

El Sr. Torralbo no quiso admitir siquiera discusión sobre la base de cederme por precio alguno las monedas: manifestando que, por conocerle a Ud., estaba seguro de que si tal hiciese, la respuesta de Ud. sería un tiro por correo.. Espero que no hubiera trascendido a tamaña consecuencia el enojo de Ud. Mas ante la manifestación que hacía de su deseo de aquellas monedas figurasen unidas a mi colección por donación de Ud. solo me restaba encargarle que le hiciera presente el testimonio de mi gratitud, que ahora personalmente la notifico.

No es especial afición numismática la mía. He reunido monedas españolas arábigas y cristianas, de la Edad Media, a título más bien de documentos en cuya epigrafía y arte puedan contrastarse los elementos de estudio de artes industriales en que fuimos maestros en aquellos siglos. Es notorio, aun cuando la noticia no tenga para que trascender del círculo de mis amistades íntimas, que los objetos que mi mujer y yo hemos ido reuniendo, unidos a la colección formada en vida por mi suegro (q.e.p.d) no habrán de dispersarse al azar de ningún abandono, ni salir ciertamente de España, como salen tantas otros recuerdos de tiempo pasado. Si algún día, según espero, reviste realidad el Instituto de Valencia de Don Juan, constará que entre sus colaboradores se ha contado Ud.

Ahora bien, otro favor deseara merecerle. Como ya he dicho, el interés de hallazgos de monedas antiguas consiste principalmente en las deducciones que pueden formularse sobre la coincidencia de fechas y procedencia de monedas que circularon juntas y juntas quedaron soterradas. Por punto general, se aprovechan escasamente tales ocasiones. Las monedas halladas juntas se dispersan, y cuando ya andan cada una por su lado y no cabe confrontar unas con otros cuños, es cuando llega a saberse que se encontraron juntas. Pues bien: alguno de los amigos que en esta s/c suelen reunirse para charlar de cosas de antaño, quiere escribir para la revista Cultura española alguna noticia y comentario de aquel hallazgo de Carmona. ¿Sería Ud. tan bueno que me proporcionase cuantos datos personalmente haya conocido acerca de él; de cómo y en qué forma se encontraron las monedas (si en este detalle se quisiera guardar 
reserva, basta con saber que fue en término de Carmona); de cuántas, aproximadamente, se encontraron; si eran todas por el estilo de las que aquí tenemos; si, mezcladas con ellas, se encontró alguna moneda de cobre, etc. etc; $y$, sobre todo, si se encontraron juntas todas ellas, o en diferentes ocasiones o sitios.

Agradeciendo a Ud. de antemano, y mucho, las noticias que en el particular me proporcione, se ofrece a Ud. atento s.s.q.b.s.m.

Guillermo de Osma

\section{Carta $n^{\circ} 3$}

El Ministro de Hacienda

Madrid, 20 de noviembre 1907

\section{Sr. D. Juan Fernández López}

Muy señor mío y estimado amigo:

(...)

Son muy interesantes las indicaciones e hipótesis que V. formula. Ya dije a V. que alguno de nuestros amigos hará algún estudio del hallazgo de monedas de Carmona, tan pronto como podíamos ordenar todas las noticias que con él se relacionan19. Y sobre este punto suplico a V. que nos aclare si formaba parte del hallazgo alguna moneda que no fuere del tipo de las que aquí tengo, de leyendas arábigas.

Respecto de éstas, ya sabe V. cuánto me interesa el cotejo de cecas y de fechas. Sería de interés inapreciable, ascendiendo nada menos que a 200 el número de las piezas, saber si estas se hallaron en una vez juntas. Muchísimo agradeceremos a V. que recoja en este particular el testimonio mío, a ser posible, de los mismos que las hallaron.

Están las monedas tan oxidadas, que temo que no se puedan sacar improntas de ellas: pues algunas literalmente, se pulverizan, lo mejor, sin duda alguna, sería recogerlas, siquiera para poder leer todas las leyendas. Comprendo la dificultad que ello ofrezca, una vez dispersas en poder de distintos dueños, y no habiendo caso ahí quien con facilidad pueda leer el año de la cuñación y el nombre de la ciudad donde se acuñaron: siendo idénticas (como lo son en las que aquí hemos visto), las leyendas de las orientales y las andaluzas. Estas últimas son de las que tienen para mí interés directo, y me da mucha fatiga el pensar que varias o muchas se dispersen juntamente con las orientales. Si quisiera V. hacerme el favor de recibir en el particular mis plenísimos poderes para cualquier rescate, se lo agradeceríamos mucho en nombre del interés arqueológico. Propiamente, coleccionistas de nuestras monedas arábigas de aquel tiempo puede decirse que ahora no los hay; pero yo con muchísimo gusto recogería, a duro, todas las que fuesen españolas, y dos duros, todas las que dieren distintas fechas o cecas; o estuviesen mejor conservadas. La dificultad estriba, claro es, en que los actuales dueños de las monedas dispersas pudiesen ellos mismos distinguir las orientales de las andaluzas, o en que quisieran fiarse de nosotros para leerlos.

En último término, y aunque hubiera naturalmente de ser el precio menor, convendría recogerlas todas, para poderlas ver de una vez, ya que no puedo coger el tren e irme a Carmona a verlas.

De todas suertes, repito que, a los efectos de la rebusca y rescate, tiene $\mathrm{V}$. plenos poderes para todo cuanto todavía sea tiempo de llevar cabo, quedándose además, y siempre, muy obligado su afmo. amigo q.b.s.m.

Guillermo de Osma

\section{Carta ${ }^{\circ} 4$}

El Ministro de Hacienda

Madrid, 24 de diciembre 1907

Sr. D. Juan Fernández López

Mi querido amigo:

Muchas gracias, en nombre también de todos los Señores del margen, por su última y tan interesante carta; y gracias especiales mías por la marcha de la recolección y rescate de las monedas.

Por lo que rezan las improntas, solo una de las últimas piezas rescatadas es andaluza. En cambio, parece ser de cuño distinto de las anteriormente recogidas. La proporcionalidad es, por de contado, problema purísimamente de suerte y casualidad, pues hasta aquí, al fin y al cabo, solo llevamos conocidas, entre todas, unas sesenta monedas de doscientas y pico que se hallaron.

(... )

Le deseamos muy felices pascuas y es siempre suyo afmo. amigo q.b.s.m.

Guillermo de Osma 


\section{Carta $\mathbf{n}^{\circ} 5$}

El Ministro de Hacienda

Madrid, 28 de enero de 1908

Sr. D. Juan Fernández López

Mi querido amigo:

(...)

Por cierto que en una de sus cartas anteriores me recuerda V. que, escribiendo un domingo, hablé de los señores al margen, pero el margen iba en blanco. Como curiosidad, envío a V. la lista de los que aquel día asistieron a su tertulia dominguera, de la que es V. vocal honorario y correspondiente, mientras nos haga V. una visita y sienta plaza de número.

Tan pronto como llegue D. Lorenzo, se citará a estudio serio y formal de las monedas por la bondad de V. recogidas.

Desde luego se le enviará a V. nota de las cecas y fecha. Sin duda alguna las habrá repetidas, principalmente entre las orientales, pero con algunas resultan ser andaluzas y de años distintos, todas y cada una de las del hallazgo merecerán la bienvenida de nuestra gratitud.

No me dice V. en su carta las cantidades que haya tenido la bondad de invertir por mi cuenta en la campaña de rescate. Le suplico este dato, de formalización y como remate de su bondad.

Improntas de todas las que falten, de dicho hallazgo, siempre sería conveniente [sic], para los efectos de comprobación y comentario. Siempre suyo afmo. amigo q.b.s.m.

Guillermo de Osma

\section{$\operatorname{Carta~}^{\circ} 6$}

El Ministro de Hacienda

9 de febrero de 1908

\section{Sr. D. Juan Fernández López}

Mi querido amigo:

Acompaño la nota que $\mathrm{V}$. deseaba (que aquí tengo desde el domingo, para enviársela) de las cecas y variantes que se encuentran entre las monedas que trajo el amigo D. Lorenzo.

Sirva también el análisis, de que es resumen esta nota para la Cultura: que yo cuidaré que oportunamente se le envíe.
Hay, con efecto, elementos ya bastantes, con las monedas que se tienen a la vista, para emprender el estudio del hallazgo: pues entre todas ya se acercará a una mitad de las halladas las que se han descifrado.

Como V. verá, son muchas las variantes de las cecas y de años entre las orientales.

Las andaluzas, que más directamente nos interesan, se han hallado por desgracia en menor número y proporción entre las que ahora se han recolectado. Así y todo, hay una que, aunque del mismo año que una del primer envío, entraña una variante muy curiosa en el cuño.

Va copiada exactamente, en el propio carácter de letra que lleva en las monedas, la expresión de cada ceca; o sea en el caso de las que más interesan, la palabra Alandalus. Si entre las restantes del hallazgo que pudiera $\mathrm{V}$ ver, o de las que pudieran conseguirse improntas, se encontrase alguna mas de estas andaluzas, me alegraría mucho poderlas recoger.

\section{(...)}

No me encontraba violento ni molesto por nuestra tardanza en formalizar los gastos que tuvo V. la bondad de anticipar por mi cuenta en la recolección de las últimas monedas: que nada tiene que ver con el obsequio, que tanto agradecí a V. de las primeras. Se lo recordaba a $\mathrm{V}$ en mis últimas cartas, porque ya sabe $V$. que siempre fue cosa convenida que todo el gasto de seguir reuniendo estas monedas del hallazgo, se entendiera por mi cuenta: poniendo a V. el favor de su activa bondad en la resolución. En esta carta envío a V. su importe de 500 pesetas, quedándole siempre agradecidísimo.

(...)

Suyo siempre afmo. amigo q.b.s.m.

Guillermo de Osma

\section{$\operatorname{Carta~}^{\circ} 7$}

El Ministro de Hacienda

Madrid, 16 de febrero de 1908

Sr. D. Juan Fernández López

Mi estimado amigo:

Contesto sus dos cartas del 12 y del 14: (...)

Monedas.- Con efecto, la moneda número 4 del primero envío es del año 93, y no del 90. También es así que dos de las siete andaluzas del primer envío eran duplicadas. 
Así mismo, en el segundo envío, la diferencia de 57 a 59 , número de las monedas, se halla en dos que se han podido leer y veinte que son duplicadas; casi todas de Wasit.

Por cierto que entre los tres fragmentos que también venían en el segundo lote, uno es, por lo que puede leerse de la fecha, debió ser el más antiguo de todos. También del primer lote, la más antigua fue la que se malogró en el viaje; si bien, para los efectos del comentario y del artículo, son firmes los datos de ambas.

Si entre los 70 ú 80 que quedan sueltas hubiese algunas andaluzas, interesaría doblemente recogerlas, por si reprodujeran alguna de estas dos fechas que son A. H. 205 y 108.

(...)

Suyo afmo. q.b.s.m.

Guillermo de Osma

(...)

\section{Carta ${ }^{\circ} 8$}

El Diputado a Cortes por Monforte

Madrid, 29 de junio de 1908

Sr. D. Juan Fernández López
Mi distinguido amigo:

Antes de salir de Madrid a veraneo, que acaso se prolongue, en busca de salud, y ya que V. no ha podido asistir, este año, como vocal honorario a ninguna de las reuniones del dominguero sanedrín, desearía preguntarle: si ha salido alguna moneda más suelta, de las andaluzas, de aquel hallazgo: y si cree $\mathrm{V}$ que los dueños que conservan todavía en su poder lotéenlos o monedas sueltas de aquellas, tendrían el gusto en que yo les propusiera cambio a razón de cuatro por una, de las orientales del propio hallazgo por cualquiera andaluza que todavía resultare por recoger.

Unas y otras monedas son, como V sabe, absolutamente idénticas en apariencia, época y hechura, pero me interesaría siempre recoger las que fueran andaluzas, aunque resulten duplicadas de las que ya poseo.

Queda suyo siempre afmo. Amigo q.b.s.m.

Guillermo de Osma

En el Instituto Valencia de Don Juan se conserva un informe manuscrito que sobre la composición del hallazgo de Carmona realizó Antonio Vives que ha pasado desapercibido hasta la fecha?:

\section{Tesoro de Carmona}

Monedas árabes del siglo VIII.

años 79 a 135 de la hégira 698 a 752.

listado

$2^{\circ}$ envio $^{8}$

\begin{tabular}{|c|c|c|c|}
\hline \multirow{7}{*}{ بالانـــــــــــلس } & Al-Andalus & 111 & 1 \\
\hline & & 114 & 11 \\
\hline & & 115 & 1 \\
\hline & & 116 & III \\
\hline & & 117 & 1 \\
\hline & & 135 & III \\
\hline & & “ frag & III \\
\hline \multirow[t]{2}{*}{ افريقيـــــــــة } & Ifriqiya & 103 & /I \\
\hline & & 114 & 11 \\
\hline من منــــــاذر & Menader & 80 & 1 \\
\hline رامهــــرمز & Ram Hormuz & 80 & 1 \\
\hline
\end{tabular}

7 IVDJ Manuscritos MSS $\mathrm{n}^{\circ}$ 2. Último cuadernillo -"Monedas".

8 Los datos de las monedas se han introducido en tablas para facilitar su consulta indicando la última columna de la derecha el número de ejemplares recogidos. 


\begin{tabular}{|c|c|c|c|}
\hline رامهــــرمز & Ram Hormuz & 80 & 1 \\
\hline همـــــــان & Hamadan & 80 & 1 \\
\hline سحســـان & Sidyistan & 90 & 1 \\
\hline سرخس & Sarakhs & 92 & 1 \\
\hline دســـتوا & Destawa & 93 & 1 \\
\hline جu & Djeyy & 94 & 1 \\
\hline خــرة اردشـــــر & & 95 & 1 \\
\hline إمـاهي & Mahi & 95 & 1 \\
\hline كرمــان & Kerman & 103 & 1 \\
\hline الاهــــــواز سـوق & Suk Al Ahuaz & "4 frag & 1 \\
\hline البصـــــره & & 100 & 1 \\
\hline \multirow{2}{*}{ دربجـــرد } & Darabjird & 92 & 1 \\
\hline & & 97 & 1 \\
\hline \multirow{2}{*}{ ســــابور } & & 81 & 1 \\
\hline & & 92 & 1 \\
\hline \multirow[t]{23}{*}{ واسـط } & & 84 & 11 \\
\hline & & 85 & 1 \\
\hline & & 86 & III \\
\hline & & 87 & 1 \\
\hline & & 89 & 1 \\
\hline & & 90 & 1 \\
\hline & & 91 & 1 \\
\hline & & 92 & III \\
\hline & & 93 & III \\
\hline & & 94 & III \\
\hline & & 95 & III \\
\hline & & 99 & 11 \\
\hline & & 108 & 1 \\
\hline & & 109 & 1 \\
\hline & & 110 & 1 \\
\hline & & 111 & 1 \\
\hline & & 112 & 1 \\
\hline & & 113 & 1 \\
\hline & & 114 & 1 \\
\hline & & 117 & 1 \\
\hline & & 120 & 1 \\
\hline & & 121 & 1 \\
\hline & & 123 & 1 \\
\hline \multirow[t]{8}{*}{ دمسـق } & & 83 & 1 \\
\hline & & 84 & III \\
\hline & & 90 & 1 \\
\hline & & 91 & 1 \\
\hline & & 92 & 1 \\
\hline & & 96 & 1 \\
\hline & & 97 & 1 \\
\hline & & 113 & 1 \\
\hline _- & & 92 & 1 \\
\hline \multirow[t]{3}{*}{ (n) } & & 92 & 1 \\
\hline & & Fragmento & 1 \\
\hline & & Borrosa & 1 \\
\hline
\end{tabular}




\begin{tabular}{|c|c|c|c|}
\hline \multirow[t]{5}{*}{ 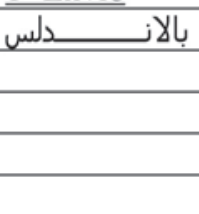 } & & 108- rota & 1 \\
\hline & & 111 & 1 \\
\hline & & 117 & 1 \\
\hline & & 129 & III \\
\hline & & 131 & 1 \\
\hline الباصـــــــره & & 79 & 1 \\
\hline دمسـق & & 89 & 1 \\
\hline واســـ & & 90 & 1 \\
\hline جى & & 93 & 1 \\
\hline دربحــــرد & & 93 & 1 \\
\hline قــومس & Kumes & 93 & 1 \\
\hline \multirow[t]{2}{*}{ اصـطـحر } & /s'thakhr & 96 & 1 \\
\hline & & 97 & 1 \\
\hline واســــ & & 99 & 1 \\
\hline البصـــــره & & 100 & 1 \\
\hline \multirow[t]{2}{*}{ واســـ } & & 108 & 1 \\
\hline & & 109 & 1 \\
\hline دمســق & & 111 & 1 \\
\hline وواســـ & & 120 & 1 \\
\hline
\end{tabular}

\begin{tabular}{|c|c|c|}
\hline \multicolumn{3}{|l|}{$3^{\circ}$ enví́ } \\
\hline بســــــــور & 96 & / regalada \\
\hline بــــــــ & 80 & / regalada \\
\hline bــــــــ & 118 & / regalada \\
\hline 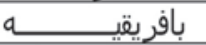 & 110 & / regalada \\
\hline بالانـــــــــلس & 129 & / regalada \\
\hline \multicolumn{3}{|l|}{11111111} \\
\hline بـــــــدربحرد & 91 & 1 \\
\hline 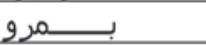 & 101 & 1 \\
\hline باصــــحر & 96 & 1 \\
\hline بــــــاهي & 90 & 1 \\
\hline \multirow[t]{2}{*}{ 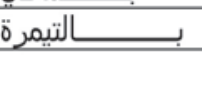 } & 91 & 1 \\
\hline & 92 & 1 \\
\hline \multirow[t]{9}{*}{ بواســــ } & 84 & 1 \\
\hline & 85 & II \\
\hline & 86 & IIII \\
\hline & 94 & 1 \\
\hline & 96 & 1 \\
\hline & 98 & 1 \\
\hline & 105 & 1 \\
\hline & 111 & 1 \\
\hline & 121 & 1 \\
\hline \multirow[t]{2}{*}{ بذمســـق } & 79 & 1 \\
\hline & 111 & 1 \\
\hline 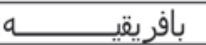 & 104 & 1 \\
\hline \multirow[t]{4}{*}{ بالانانـــــــــلس } & 110 & 1 \\
\hline & 116 & 11 \\
\hline & 129 & $1 /$ \\
\hline & 135 & IIII \\
\hline \multicolumn{3}{|l|}{1111111111} \\
\hline بــــــــروو & 91 & 1 \\
\hline \multirow{3}{*}{ bـــــــ } & 89 & 1 \\
\hline & 93 & 1 \\
\hline & 122 & 1 \\
\hline 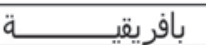 & 105 & 1 \\
\hline بالالانـــــــــــ & 106 & 1 \\
\hline
\end{tabular}


[conjunto total]

\begin{tabular}{|c|c|c|c|}
\hline \multirow{2}{*}{ البصــــــر } & Albasora & 79 & 1 \\
\hline & " & 100 & 1 \\
\hline جي & Djeyy & 93 & 1 \\
\hline دربجــــرد & Darabjerd & 93 & 1 \\
\hline قــومس & Kumes & 93 & 1 \\
\hline \multirow[t]{2}{*}{ اصـطخر } & Istakhar & 96 & 1 \\
\hline & " & 97 & 1 \\
\hline \multirow[t]{5}{*}{ واسـطـ } & Wasit & 90 & 1 \\
\hline & “ & 99 & 1 \\
\hline & “ & 108 & 1 \\
\hline & “ & 109 & 1 \\
\hline & “" & 120 & 1 \\
\hline \multirow[t]{2}{*}{ دمسـق ق } & Damasco & 98 & 1 \\
\hline & " & 111 & 1 \\
\hline \multirow[t]{5}{*}{ الانــــــــــلس } & Alandalus & 108 rota & 1 \\
\hline & " & 111 & 1 \\
\hline & “ & 117 & 1 \\
\hline & “ & 129 & III \\
\hline & “ & 135 & 1 \\
\hline منــــــــاذر & Menader & 80 & 1 \\
\hline رامــــــرمز & Ramhormuz & 80 & 1 \\
\hline هــــــدان & Hamadan & 80 & 1 \\
\hline سحســـــان & Sidjistan & 90 & 1 \\
\hline سرخس & Sarakhs & 92 & 1 \\
\hline دســــتوا & Dastawa & 93 & 1 \\
\hline جي & Djeyy & 94 & 1 \\
\hline 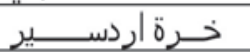 & & 95 & 1 \\
\hline لمــــاهي & Mahi & 95 & 1 \\
\hline كرمـــان & Kerman & 103 & 1 \\
\hline الاهـــــــــــــــــ & Suk Alahuaz & "4 frag & 1 \\
\hline البصــــــر & Albasora & 100 & 1 \\
\hline \multirow[t]{2}{*}{ دربجــــرد } & Darabjerd & 92 & 1 \\
\hline & “ & 97 & I \\
\hline \multirow[t]{2}{*}{ ســــابور } & Sabur & 81 & 1 \\
\hline & “ & 92 & 1 \\
\hline واســط & Wasit & 84 & 1 \\
\hline " & " & 85 & 1 \\
\hline$"$ & " & 86 & III \\
\hline$"$ & “" & 87 & 1 \\
\hline$"$ & “ & 89 & I \\
\hline$"$ & “ & 90 & 1 \\
\hline$"$ & “ & 91 & 1 \\
\hline$"$ & " & 92 & III \\
\hline$"$ & " & 93 & III \\
\hline$"$ & " & 94 & III \\
\hline$"$ & " & 95 & III \\
\hline$"$ & " & 99 & 11 \\
\hline " & “" & 108 & 1 \\
\hline$"$ & “ & 109 & 1 \\
\hline$"$ & " & 110 & 1 \\
\hline
\end{tabular}




\begin{tabular}{|c|c|c|c|}
\hline$"$ & "“ & 111 & 1 \\
\hline " & " & 112 & 1 \\
\hline$"$ & "“ & 113 & 1 \\
\hline$"$ & “" & 114 & 1 \\
\hline “ & “ & 117 & l \\
\hline$"$ & “ & 120 & I \\
\hline$"$ & $“$ & 121 & 1 \\
\hline$"$ & " & 123 & 1 \\
\hline$"$ & $"$ & "4 & 1 \\
\hline دمسـق & Damasco & 83 & 1 \\
\hline " & “ & 84 & /1 \\
\hline " & " & 90 & 1 \\
\hline$"$ & $"$ & 91 & 1 \\
\hline$"$ & $"$ & 92 & 1 \\
\hline “ & $"$ & 96 & I \\
\hline “ & “ & 97 & I \\
\hline “ & $"$ & 113 & I \\
\hline ـــرابرســــ] & & 92 frag & 1 \\
\hline 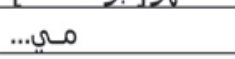 & & 92 frag & 1 \\
\hline$\ldots .$. & $\ldots \ldots \ldots$ & Frag & 1 \\
\hline$\ldots .$. & $\ldots \ldots \ldots$ & Borrosa & 1 \\
\hline 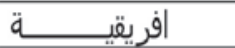 & Afriquia & 103 & $1 /$ \\
\hline$"$ & “ & 114 & /I \\
\hline الانـــــــــلس & Alandalus & 111 & 1 \\
\hline " & " & 114 & // \\
\hline$"$ & " & 115 & I \\
\hline$"$ & $"$ & 116 & /II \\
\hline$"$ & " & 117 & 1 \\
\hline$"$ & " & 135 & III \\
\hline$"$ & “ & frag & III \\
\hline
\end{tabular}

Las monedas contenidas en este depósito comprenden un lapso de tiempo de medio siglo desde el año 79 á 135 de la Hégira 692 a 752 de J.C. Son por lo tanto de las llamadas de tipo Omeya, conteniendo sólo leyendas religiosas sin más distintivos que el del punto de acuñación o ceca y la fecha.

Las cecas son en su mayoría de oriente siendo abundantes las de Damasco y sobre todo las de Wasit de donde se deduce que estas dos cecas eran las que producían la mayoría de los dirhemes circulantes.

La mayoría de las cecas orientales están representadas por una sola fecha y un solo ejemplar, la ceca de Damasco comprende las fechas desde el 83 al 113 y once ejemplares; la de Wasit, comprende 24 fechas de 84 a 123 y 41 ejemplares.
La multitud de cecas de oriente contrasta con las poquísimas que se conocen en occidente; tan sólo dos de estas cecas produjeron numerosas en esa época, mejor dicho en el siglo siguiente, puesto que la de, Afriquia= Cairuan, no se conocían a fecha anterior al 101 y de $=$ Al-Andalus= Córdoba, la fecha más antigua es 104.

En este hallazgo la ceca de África está representada por dos fechas 103 y 114 dos ejemplares cada una y la de España, por 8 fechas de 108 a 135 y 21 ejemplares.

Los hallazgos de monedas orientales de esta época no son raros, en España, en cambio los de ceca española lo son mucho, por lo tanto la cosa no se explica más que admitiendo que la acuñación era aquí muy reducida cosa que confirma este depósito pues la proporción de un $29 \%$ de ceca española es cosa increíble. 


\begin{tabular}{|c|c|c|c|c|c|c|c|}
\hline Paris & $\begin{array}{l}\text { Мo } \\
\text { Arqo }\end{array}$ & $\begin{array}{l}\text { Col } \\
\text { Gayangos } \\
\text { o Codera }\end{array}$ & $\begin{array}{l}\text { Fdez } \\
\text { Guerra }\end{array}$ & Fraehn & Hallemberg & Tornberg & $\begin{array}{l}\mathrm{T} \text {. } \\
\text { Carmona }\end{array}$ \\
\hline 106 & 108 & 116 & 129 & 104 & 107 & 130 & 105 \\
\hline 111 & 118 & & & 105 & & & 108 \\
\hline 113 & 131 & & & 110 & & & $111 /$ \\
\hline 114 & & & & 121 & & & $1110 /$ \\
\hline 115 & & & & 125 & & & 114 \\
\hline 118 & & & & & & & $115 /$ \\
\hline & & & & & & & $\begin{array}{l}116 \\
/ / /\end{array}$ \\
\hline & & & & & & & $117 /$ \\
\hline & & & & & & & $\begin{array}{l}129 \\
/ / /\end{array}$ \\
\hline & & & & & & & $\begin{array}{l}135 \\
/ / / / /\end{array}$ \\
\hline
\end{tabular}

como se ve a pesar de la rareza de estas monedas no deja de cumplirse la regla general y lógica de que los últimos años tienen mucho mayor número de ejemplares.

En cambio en las cecas orientales, mejor dicho en la de Wasit, .......abundancia solo tres fechas repiten los ejemplares y no son con mucho de los últimos años. De modo que aunque no se supiera la procedencia de este hallazgo la proporción de las piezas conservadas nos da a entender se habrá encontrado en España.

La última fecha española es el 135 y el depósito debió hacerse en ese mismo año, y no después, pues no sólo es la última fecha sino que las monedas (6 ejempls.) están en un estado de conservación perfecto, salvo las roturas por la oxidación, prueba evidente de su poca circulación.

Tres años después de la última fecha de estas monedas en 138, Abderrahman se apoderó del mando de la España Árabe, dejando de pertenecer al califato de oriente o mejor dicho el califato de oriente había dejado de pertenecer a los Omeyas y su descendiente se había refugiado en España continuando aquí la dinastía, y así se ... .... que mientras en oriente se cambiaban las leyendas de las monedas, en España se sigue acuñando el mismo tipo por espacio de siglo y medio.
Es verdad que desde el 135, última fecha conocida, de las monedas de la España dependiente de oriente hasta la $1^{\text {a }}$ fecha de Abderrahman I, 148, median doce años, pero no es fácil si esta laguna se llenará con futuros descubrimientos. Lo cierto es que en las monedas no se nota cambio alguno, y no sería extraño que se fabricaran seguidas o sin interrupción desde 135 última conocida del régimen antiguo y el 148, primera del nuevo gobierno, es más el día que se conozca la moneda del año 138 no se sabría a punto fijo a cual de los dos grupos debe aplicarse.

Sería curioso un análisis del metal con que se acuñaron estos dirhemes, porque ocurre una particularidad: todas las piezas tienen un estado particular de oxidación producido sin duda por vapores de sales sulfurosas produciendo un metal agrio y muy frágil que las orientales han resistido bastante sin romperse pero en cambio las españolas se rompen con la mayor facilidad. En el $\mathrm{M}^{\mathrm{o}}$. Arqueológico se conservan unos fragmentos de un dirhem de 118, siendo este, con un dirhem de cobre plateado del año 131 lo único que de esa serie guarda dicha colección (1).

En un ejemplar del 111 se presenta un modelo o variación de gran elegancia consistente en que además de un gran esmero en el trazado de 
las leyendas, la orla de la $1^{\mathrm{a}}$ Área está separada de la inscripción del campo por un círculo, que le da un aspecto elegantísimo; ese mismo círculo aparece luego hacía los años 220 y siguientes pero no tiene la perfección y elegancia que se ve en este .

\section{ArTe}

Dice Codera en su tratado de Monedas Arábigo-españolas que las primeras monedas de Alandalus están copiadas de Wasit, la observación es justa respecto a los primeros 20 años, luego se diferencias bastante pareciéndose más a las de Damasco, por lo que se ve que el gra- bador de cuños copia las monedas que tenía entre sus manos.

En cambio las de ceca Afriquia son copia evidente de las de Damasco y el tipo previsto en dicha ceca.

El ejemplar que publicamos en el catálogo -tal- y en la obra Monedas de las dinastías Arábigo-españolas, $\mathrm{n}^{\circ} 24$, con fecha de 108 , es muy posterior resultando la fecha ser un error del cuño.

En el fichero de la ceca del Instituto Valencia de Don Juan', se han localizado las siguientes referencias:

\begin{tabular}{|c|c|c|c|c|c|}
\hline Ceca & Año & Peso & Módulo & $\begin{array}{l}\text { № dentro } \\
\text { de la } \\
\text { colección }\end{array}$ & Comentarios \\
\hline Ifriqiya & 103 & 2,80 & 26 & 259 & \\
\hline Ifriqiya & 104 & 2,80 & 26 & 260 & \\
\hline Ifriqiya & 110 & 2,90 & 29 & 261 & \\
\hline Ifriqiya & 114 & 2,80 & 28 & 263 & \\
\hline Ifriqiya & 114 & & & 263 & \\
\hline Al-Andalus & 105 & 2,90 & 27 & 274 & \\
\hline Al-Andalus & 105 & & & 274 & $\begin{array}{l}\text { duplicado } \\
\text { roto }\end{array}$ \\
\hline Al-Andalus & 106 & 2,90 & 27 & 275 & \\
\hline Al-Andalus & 108 & 2,50 & 27 & 276 & $\begin{array}{l}\text { fragmento } \\
\text { falta lus y } \\
\text { sanata }\end{array}$ \\
\hline Al-Andalus & 110 & 2,80 & 27 & 277 & \\
\hline Al-Andalus & 111 & 2,80 & 28 & 278 & \\
\hline Al-Andalus & 111 & 2,80 & 27 & 279 & Orla circular \\
\hline Al-Andalus & 114 & 2,80 & 29 & 280 & \\
\hline Al-Andalus & 115 & 2,80 & 28 & 281 & \\
\hline Al-Andalus & 116 & 2,80 & 27 & 282 & \\
\hline Al-Andalus & 116 & & 26 & 282 & \\
\hline Al-Andalus & 117 & 2,80 & 27 & 283 & \\
\hline Al-Andalus & 117 & 2,70 & & 283 & \\
\hline Al-Andalus & 129 & 2,80 & 27 & 284 & \\
\hline Al-Andalus & 129 & & & 284 & \\
\hline Al-Andalus & 135 & 2,80 & 27 & 285 & \\
\hline Al-Andalus & 135 & & & 285 & \\
\hline
\end{tabular}

9 Para facilitar su consulta, estos datos se han transcrito introduciéndolos en una tabla. 
Y en el Museo Arqueológico Nacional se conserva el Expediente MAN 1910/42, que dice asî (Grañeda, 2009: 774, fig. 2):

" ${ }^{\circ}$ En 12 de Junio Dn Ant ${ }^{\circ}$ Vives autorizado por otra persona cuyo nombre se reserva entrega en la sección de Numismática dos dírhem de los años 116 el uno y del 135 el otro.

$2^{\circ}$ En 10 de Agosto el mismo señor y en la misma forma entrega 56 dirhem y dos fragmentos todos de cecas orientales excepto uno que es de la ceca Elandalus y del 129 de la Hegira”.

Una vez localizada toda la documentación, fue interesante, a través de los listados de los 3 envíos, poder realizar una reconstrucción del conjunto monetario, la catalogación de las piezas que lo componen y, en determinados casos, la colección en la que se depositó ${ }^{10}$ :

\begin{tabular}{|c|c|c|c|c|}
\hline Ceca & $\begin{array}{l}\text { Fecha } \\
\text { acuñación } \\
\text { (Hégira) }\end{array}$ & № ejemplares & $\begin{array}{l}\text { Referencia } \\
\text { bibliográfica }\end{array}$ & Colección \\
\hline Ardasir Jurra & 95 & 1 & Klat 39 & \\
\hline \multirow[t]{2}{*}{ Istajr } & 96 & 2 & Klat 78 & \\
\hline & 97 & 1 & Klat 79 & \\
\hline \multirow[t]{5}{*}{ Ifriqiya } & 103 & 2 & Klat 90 & IVDJ \\
\hline & 104 & 1 & Klat 91 & IVDJ \\
\hline & 105 & 1 & Klat 92 & IVDJ $^{11}$ \\
\hline & 110 & 1 & Klat 97 & IVDJ \\
\hline & 114 & 2 & Klat 101 & IVDJ- 2ej \\
\hline \multirow[t]{12}{*}{ Al-Andalus } & 106 & 1 & Klat 119 & IVDJ \\
\hline & 108 & 1 & Klat 121 & IVDJ \\
\hline & 110 & 1 & Klat 123 & IVDJ \\
\hline & 111 & 2 & Klat 124 & IVDJ-2 ej \\
\hline & 114 & 2 & Klat 127 & IVDJ \\
\hline & 115 & 1 & Klat 128 & IVDJ \\
\hline & 116 & 5 & Klat 129 & $\begin{array}{l}\text { IVDJ -2 ej } \\
\text { MAN }\end{array}$ \\
\hline & 117 & 2 & Klat 130 & IVDJ-2 ej \\
\hline & 129 & 6 & Klat 138 & $\begin{array}{l}\text { IVDJ-2 ej } \\
\text { MAN } \\
\text { British } \\
\end{array}$ \\
\hline & 131 & 1 & Vives 39 & \\
\hline & 135 & 7 & $\begin{array}{l}\text { Morgenstern } \\
\text { 86-87; Canto e } \\
\text { Ibrahim 18-19. }\end{array}$ & $\begin{array}{l}\text { IVDJ- } 2 \text { ej } \\
\text { MAN }\end{array}$ \\
\hline & fragmento & 3 & & \\
\hline \multirow[t]{2}{*}{ Al-Basra } & 79 & 1 & Klat 168 & \\
\hline & 100 & 2 & Klat 172 & \\
\hline \multirow[t]{2}{*}{ Al-Taimara } & 91 & 1 & Klat 207 & \\
\hline & 92 & 1 & Klat 208 & \\
\hline \multirow[t]{2}{*}{ Yayy } & 93 & 1 & Klat 261 & \\
\hline & 94 & 1 & Klat 262 & \\
\hline
\end{tabular}

10 Según la organización presentada en la obra de Martín Escudero, 2005a; las referencias son a la obra de Klat, 2002, la mejor referencia para las monedas de esta clase.
11 Acerca de las monedas localizadas en la colección del IVDJ, véase la lámina 1 de este artículo y la documentación del fichero de la ceca de dicha institución. 


\begin{tabular}{|c|c|c|c|c|}
\hline Darabiyird & 91 & 1 & Klat 292 & \\
\hline & 92 & 1 & Klat 293 & \\
\hline & 93 & 1 & Klat 294 & IVDJ \\
\hline & 97 & 1 & Klat 298 & IVDJ \\
\hline Dastawa & 93 & 1 & Klat 312 & \\
\hline \multirow[t]{11}{*}{ Dimisq } & 79 & 1 & Klat 323 & \\
\hline & 83 & 1 & Klat 327 & \\
\hline & 84 & 3 & Klat 328 & \\
\hline & 89 & 1 & Klat 333 & \\
\hline & 90 & 1 & Klat 334 & \\
\hline & 91 & 1 & Klat 335 & \\
\hline & 92 & 1 & Klat 336 & \\
\hline & 96 & 1 & Klat 340 & \\
\hline & 97 & 1 & Klat 341 & \\
\hline & 111 & 2 & Klat 355 & \\
\hline & 113 & 1 & Klat 357 & \\
\hline Ramhurmuz & 80 & 1 & Klat 380 & \\
\hline \multirow[t]{3}{*}{ Sabur } & 81 & 1 & Klat 417 & \\
\hline & 92 & 1 & Klat 423 & \\
\hline & 96 & 1 & Klat 427 & \\
\hline Siyistan & 90 & 1 & Klat 432 & IVDJ \\
\hline Sarajs & 92 & 1 & Klat 452 & \\
\hline Suq al-Ahwaz & $\mathrm{XX} 4$ & 1 Fragmento & & \\
\hline Kumas & 93 & 1 & Klat 520 & \\
\hline Kirman & 103 & 1 & Klat 534 & \\
\hline \multirow[t]{2}{*}{ Mahi } & 90 & 1 & Klat 556 & \\
\hline & 95 & 1 & Klat 561 & \\
\hline \multirow[t]{3}{*}{ Marw } & 80 & 1 & Klat 582 & \\
\hline & 91 & 1 & Klat 588 & IVDJ \\
\hline & 101 & 1 & Klat 598 & \\
\hline Manadir & 80 & 1 & Klat 611 & \\
\hline Hamadan & 80 & 1 & Klat 663 & \\
\hline \multirow[t]{15}{*}{ Wasit } & 84 & 3 & Klat 679 & \\
\hline & 85 & 3 & Klat 680 & \\
\hline & 86 & 7 & Klat 681 & \\
\hline & 87 & 1 & Klat 682 & IVDJ \\
\hline & 89 & 2 & Klat 684 & IVDJ \\
\hline & 90 & 2 & Klat 685 & \\
\hline & 91 & 1 & Klat 686 & \\
\hline & 92 & 3 & Klat 687 & \\
\hline & 93 & 4 & Klat 688 & $\begin{array}{l}\text { IVDJ } \\
\text { IVD }\end{array}$ \\
\hline & 94 & 4 & Klat 689 & \\
\hline & 95 & 3 & Klat 690 & \\
\hline & 96 & 1 & Klat 691 & \\
\hline & 98 & 1 & Klat 693 & \\
\hline & 99 & 3 & Klat 694 & IVDJ \\
\hline & 105 & 1 & Klat 698 & \\
\hline
\end{tabular}




\begin{tabular}{|l|l|l|l|l|}
\hline & 108 & 2 & Klat 701 & British \\
\hline & 109 & 2 & Klat 702 & \\
\hline & 110 & 1 & Klat 703 & \\
\hline & 111 & 2 & Klat 704 & \\
\hline & 112 & 1 & Klat 705 & \\
\hline & 113 & 1 & Klat 706 & \\
\hline & 114 & 1 & Klat 707 & \\
\hline & 117 & 1 & Klat 710 & \\
\hline & 118 & 1 & Klat 711 & \\
\hline & 120 & 2 & Klat 713 & \\
\hline & 121 & 2 & Klat 714 & \\
\hline & 122 & 1 & Klat 715 & IVDJ \\
\hline & 123 & 1 & Klat 716 & \\
\hline xxx & 92 fragmento & 1 & & \\
\hline xxx & 92 fragmento & 1 & & \\
\hline Sin ceca & Fragmento & 1 & & \\
\hline Ilegible & Fragmento & 1 & & \\
\hline TOTAL & & 149 & & \\
\hline
\end{tabular}

Se debe señalar que no hay datos exactos sobre el conjunto total, puesto que según la correspondencia se trataba de más de 200 monedas, mientras que en la documentación encontrada hallamos detalles de sólo 146 dirhams. Estas piezas analizadas provienen de 24 cecas diferentes, siendo dos de ellas parcialmente legibles y no identificables.

El intervalo de fechas se expande desde el año 79H./698 d.C. de las cecas de al-Basra y Dimisq al 135H./752d.C. de al-Andalus, año del que existen hasta siete ejemplares. La fecha inmediatamente inferior de cierre, perteneciente a otra ceca se sitúa en el año 123H./740 d.C. de Wasit.

Respecto a los porcentajes de piezas por ceca $^{12}$ es Wasit, como viene siendo la norma general, la ceca más representada, con 57 monedas que le conceden un porcentaje del 39,33\%. Le sigue al-Andalus con $22,08 \%$ de 29 dirhams. Dimisq tiene 14 monedas, con un $9,66 \%$ e Ifriqiya $4,82 \%$ de 7 piezas. Como ya se ha indicado en otras ocasiones, la abundancia de monedas con ceca Wasit se debe a una mayor productividad de la misma en el periodo de centralización de las acuñaciones, entre los años 106 y

12 Gráficos del hallazgo de Carmona tanto de fechas cierre de cecas, como de porcentajes de moneda por ceca en Martín Escudero, 2005: 49 y figuras 19 y 20.
120H./737 d.C.(Martín Escudero, 2001: 81-94; 2005: 42-44) $)^{13}$.

De este mismo hecho resultará también una alta presencia de dírhames con ceca Dimisq, aunque habitualmente en menor número que los acuñados en Wasit. En los conjuntos monetarios de la época aparecidos en la Península Ibérica, como es lógico, también será alto, respecto al resto de cecas, el número de monedas con ceca al-Andalus.

La composición de este conjunto es similar a la de los otros hallazgos peninsulares de grandes proporciones y mejor estudiados, como es el caso del conjunto de Montillana/Iznalloz, con el que incluso comparte año de cierre, y con el de Baena. Por tanto, dichas conclusiones serán muy similares tanto para la llegada de moneda oriental en manos del yund que en el año 124H./741d.C. viene a AlAndalus para sofocar la revuelta bereber, como para los acontecimientos que quizás desencadenaron la ocultación del conjunto monetario: la llegada a al-Andalus de Abd al-Rahman I y su lucha por conseguir el poder. Debemos recordar que Carmona se encontraba dentro del territorio asignado para su asentamiento al yund de Hims.

13 Acerca de este hecho, véase Martín Escudero, 2001: 81-94 y Martín Escudero, 2005a: 42-44. 
Gracias a la correspondencia localizada, podemos saber que Archer Huntington tuvo noticia de este hallazgo pero no parece que adquiriese ninguna pieza y, aunque siempre se ha considerado que Bonsor si tuvo en su poder parte del mismo, nada en la correspondencia nos lo indica (Maier, 1999: carta ${ }^{\circ} 58$, p. 160).

Se ha localizado de la correspondencia mantenida entre Juan Férnandez y Guillermo de Osma, la remitida al primero por este segundo ${ }^{14}$. A pesar de no poder disponer del conjunto total de las cartas, podemos extraer de ellas la secuencia de los acontecimientos. Guillermo de Osma se pone en contacto con Fernández para pedirle que adquiera para él el mayor número posible de las monedas halladas en el cortijo de Santa Clara (carta 1, de 2 de noviembre de 1907).

Un día más tarde, el 3 de noviembre de 1907 (carta 2) Osma agradece a Fernández el lote de monedas que le ha regalado procedentes del tesoro de Santa Clara, le comenta, con clarividencia, que por "encontrarse juntas, y en España, más monedas acuñadas en Andalucía, con otras acuñadas en Oriente, que les sirvieran de modelo", se puede deducir que "en España circularon a una vez" y le solicita información sobre circunstancias del hallazgo tales como dónde y cómo se localizaron, cuantos ejemplares había o si se trata de un conjunto monometálico o con presencia tanto de moneda de plata como de cobre. Dichos datos son para que "alguno de los amigos que en esta s/c suelen reunirse para charlar de cosas de antaño, quiere escribir para la revista Cultura española”. Se trata de Miguel Asín Palacios que, como ya hemos indicado, publicará noticia del mismo en la revista Cultura Española. En ella analizará además las 21 monedas que en esta ocasión dona Fernández a Osma.

El 20 de noviembre de 1907 (carta 3) Ante la noticia de que el conjunto se ha dispersado ya entre varios propietarios, Osma insta a Fernández a que consiga para él el mayor número de monedas, "a duro, todas las que fuesen españolas, y dos duros, todas las que dieren distintas fechas o cecas; o estuviesen mejor conservadas" incluso todas, aunque a un precio menor, con el fin de poder extraer los datos de ceca y año de acuñación de las mismas. Le agradece los datos aportados sobre las circunstancias del hallazgo y le comenta que, por la oxidación de las piezas, algunas "literalmente, se pulverizan".

La oxidación de la que habla Osma es el realidad una mineralización de la plata debido a la alta pureza de dicho metal con el que fueron acuñadas las monedas, entre el 98-99\%, llegando en las emisiones del año 129H./746 d.C. en al-Andalus el 99,59\% (Canto e Ibrahim, 2004: 40-41 y 66; Martín Escudero, 2005: 42-43). Dicha mineralización le confiere una fragilidad extrema (Martín Escudero, 2005: 71), hecho que se puede potenciar por un proceso de fabricación diferente al del resto de talleres.

Agradece Osma el envío información y de unas 40 improntas de las monedas, entre las que tan sólo figura una andalusí, de un año ya repetido pero de distinto cuño. Estas llegarían hacia el 24 de diciembre de 1907, ya que es la fecha de la $4^{\mathrm{a}}$ carta que dirige a Fernández.

El 28 de enero de 1908 (carta 5) Osma indica a Fernández que le enviará datos de todas las monedas que le ha enviado y le insta a que consiga improntas de las monedas que no pueda adquirir. Antes de esta fecha ha debido recibir el $2^{\circ}$ lote de monedas, ya que insta a Fernández a que le indique cual ha sido el importe de estas monedas.

Por su siguiente misiva, del 9 de febrero de 1908 (carta 6) sabemos que el segundo lote ascendió a 500 pesetas, que ya está preparado el texto para la revista Cultura española y que entre las monedas de ceca al-Andalus hay dos de mismo año pero diferente cuño, puede tratarse, quizás, de los dos ejemplares del año 111H./729 d.C., ya que en todo el material consultado que alude a ambos, se indica que uno de ellos tiene orla circular interna (Fig. 1). También le remite, tras la lectura de las mismas, los datos de todas las monedas enviadas, que ya alcanzan casi la mitad de las piezas halladas. 

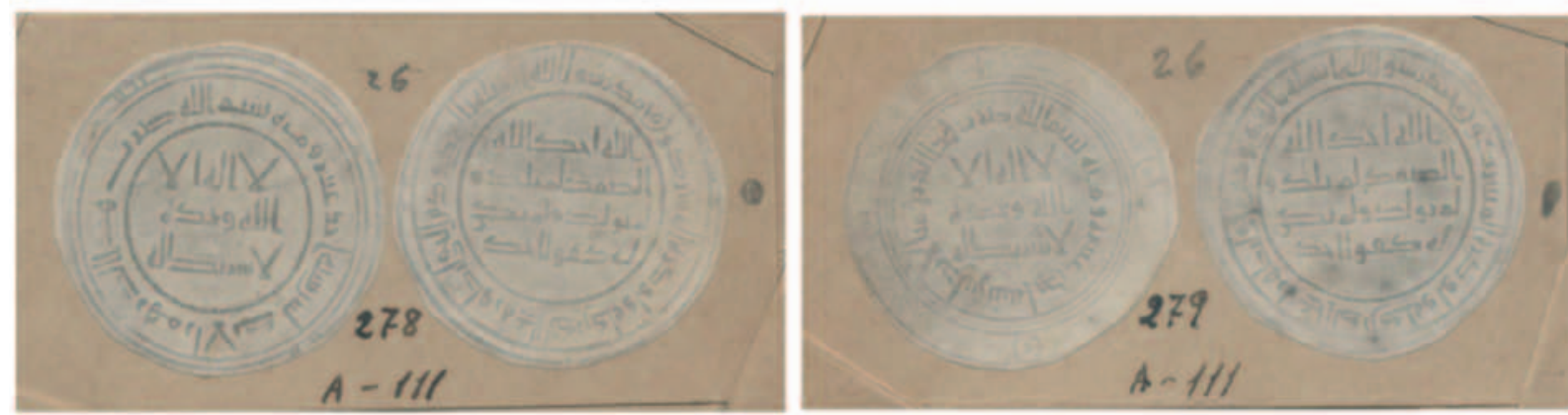

Al-Andalus $111 \mathrm{H}$.

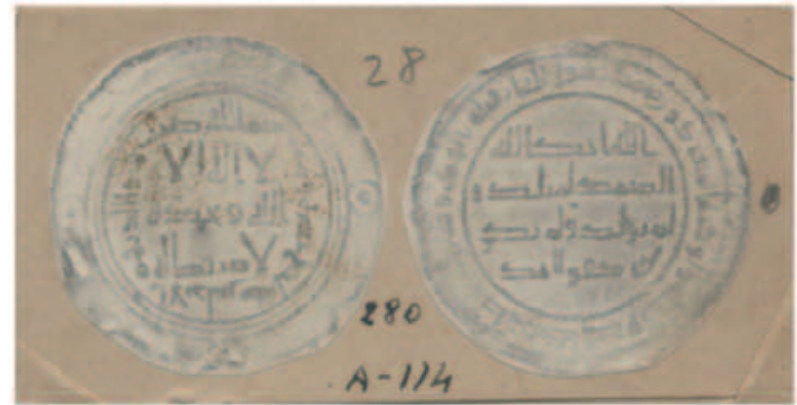

Al-Andalus 114H.

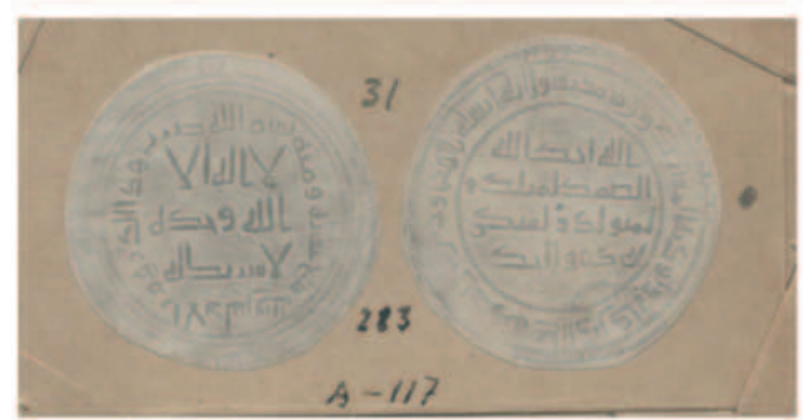

Al-Andalus 117H.

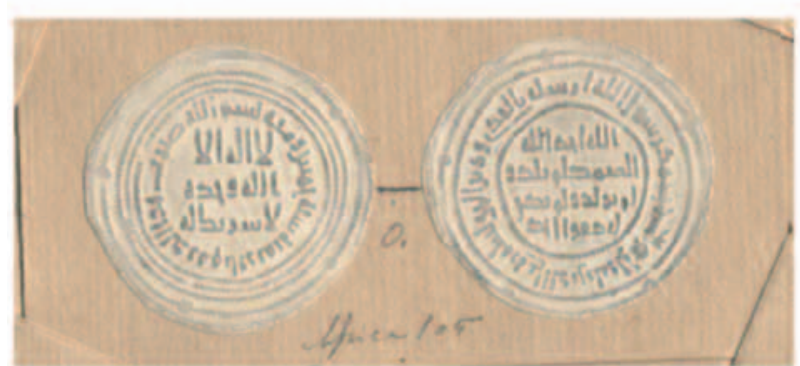

Ifriqiya $105 \mathrm{H}$.
Al-Andalus $111 \mathrm{H}$.

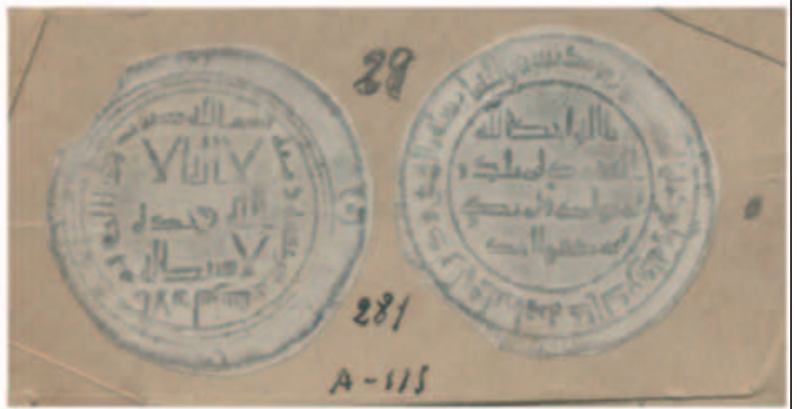

Al-Andalus $115 \mathrm{H}$.

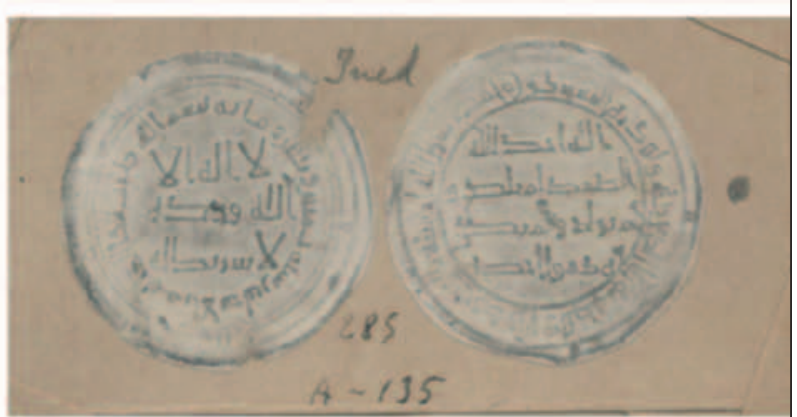

Al-Andalus 135H.

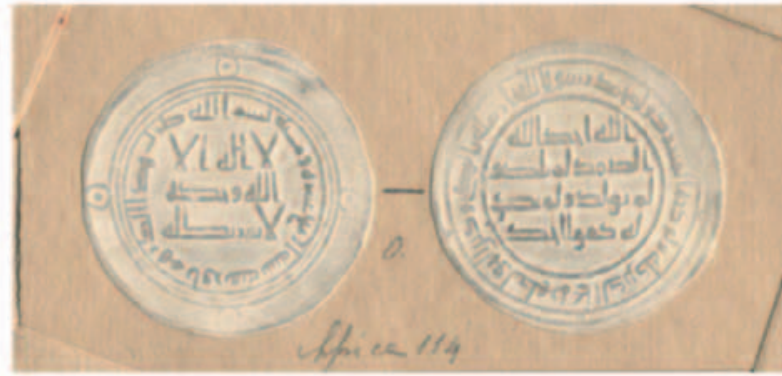

Ifriqiya $114 \mathrm{H}$.

Figura 1.- Improntas de dírhams de ceca al-Andalus e Ifriqiya del tesoro de Carmona en el IVDJ. (Estudio y clasificación del material gráfico numismático, de época andalusí, depositado en el Instituto Valencia de Don Juan de Madrid, C.M. 06/0131/2002 dir. Alberto Canto García). 


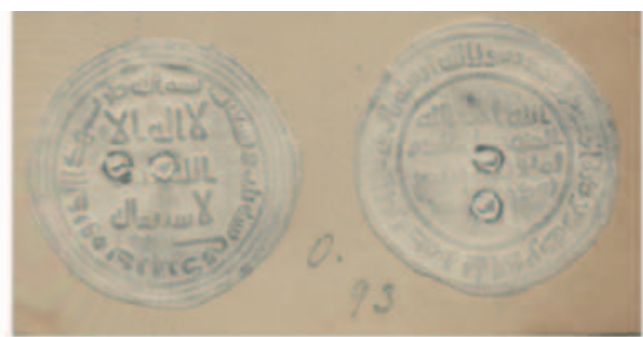

Darabiyird $93 \mathrm{H}$.

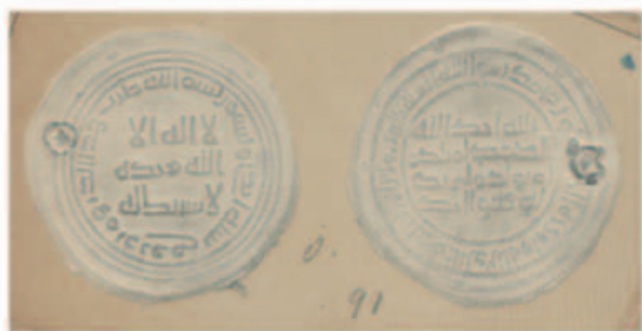

Marw 91H.

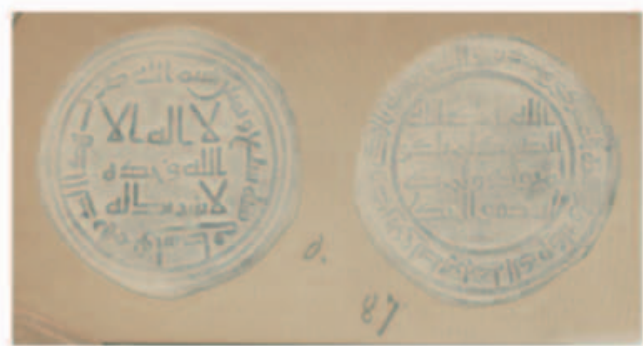

Wasit $87 \mathrm{H}$.

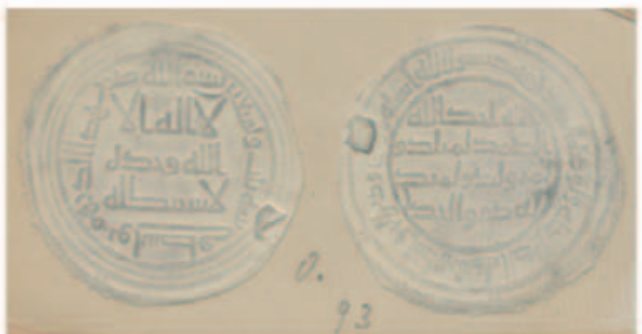

Wasit 93H.

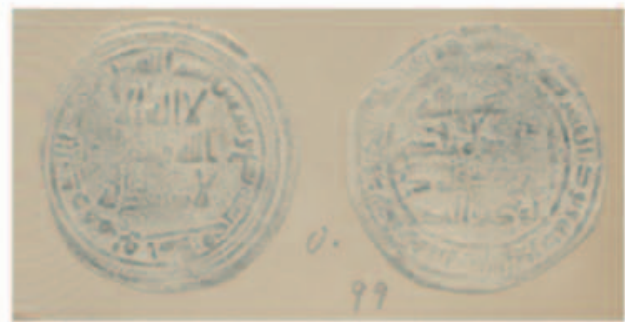

Wasit 99H.

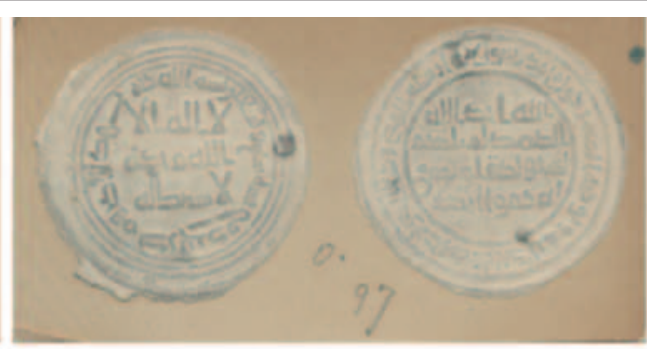

Darabiyird 97H.

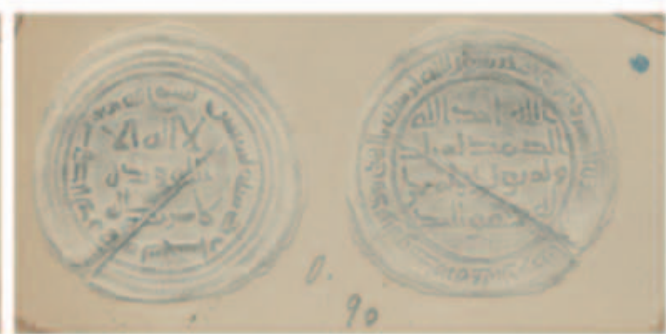

\section{Siyistan $90 \mathrm{H}$.}

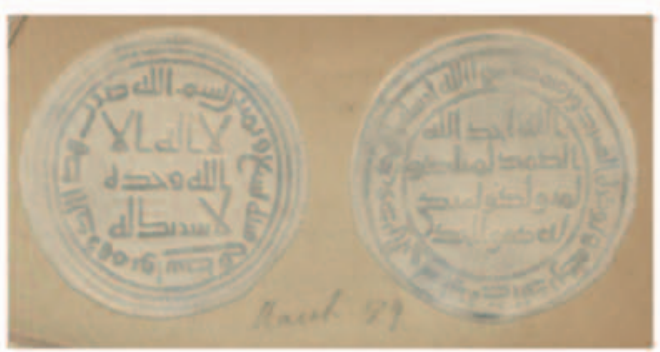

Wasit $89 \mathrm{H}$.

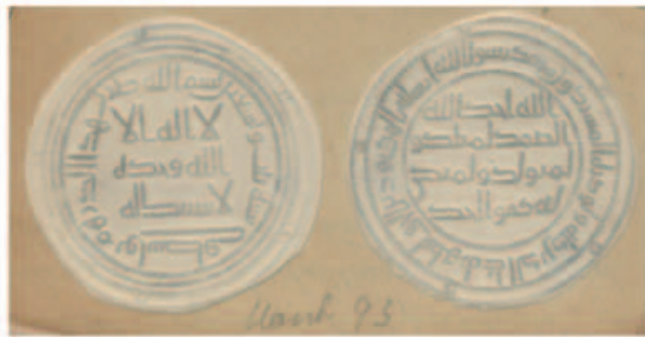

Wasit 93H.

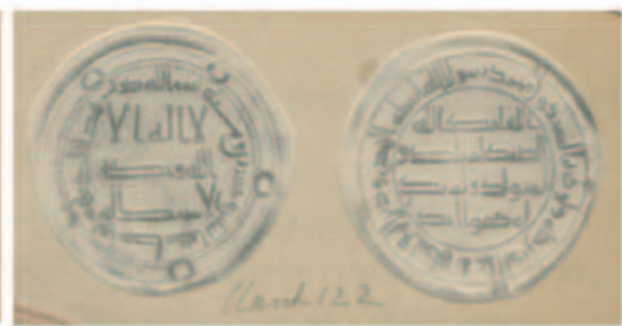

Wasit $122 \mathrm{H}$.

Figura 2.- Impronta de dírhams de cecas orientales del tesoro de Carmona en el IVDJ. (Estudio y clasificación del material gráfico numismático, de época andalusí, depositado en el Instituto Valencia de Don Juan de Madrid, C.M. 06/0131/2002 dir. Alberto Canto García). 
En la carta $n^{\circ} 7$ que dirige Osma a Fernández, fechada el 16 de febrero de 1908, informa a este sobre supuestas dudas que a Fernández le habrían surgido una vez recibida la interpretación de las monedas. Es curioso que, al solicitar más monedas, incida en su interés especial en dírhams emitidos en al-Andalus en los años 108 y 205H./726 y 820 d.C. Del primer año ya veremos cómo Vives, en su informe, duda sobre dicho año de acuñación respecto a un antiguo ejemplar de su colección, entonces ya vendida al Museo Arqueológico Nacional. Más difícil es discernir a qué se debe esa motivación espacial por la pieza del año 205H/820 d.C.

Otra duda que surge tras el análisis de esta carta es que Osma habla a Fernández del número de monedas del segundo envío, 59, sin embargo en el informe de Vives se reflejan como llegadas en este envío 83 piezas, aunque si tan sólo tenemos en cuenta las variantes de ceca y año y no los duplicados, nos encontramos con 59 monedas asignadas y una pieza borrosa.

Y en la última carta localizada, la $\mathrm{n}^{\circ} 8$, de 29 de junio, le propone un intercambio de monedas de Santa Clara: una moneda de al-Andalus, incluso de las ya duplicadas, que iría a formar parte de la colección Osma frente a 4 orientales que él entregaría al propietario de la andalusí.

A través de esta correspondencia nada más sabemos, sin embargo, en el informe que del conjunto monetario conservado en el IVDJ realiza Antonio Vives ${ }^{15}$, se indica la existencia de 3 envíos. El tercero se produciría, por tanto, en fecha posterior a la última misiva.

El denominado "Informe Vives"16, aquí transcrito y conservado en el Instituto Valencia de Don Juan proporciona una relación del conjunto y algunos comentarios sobre su composición, fechas de cierre, estado de conservación y comen-

15 IVDJ Manuscritos MSS $\mathrm{n}^{\circ}$ 2. Último cuadernillo -"Monedas".

16 IVDJ Manuscritos MSS $\mathrm{n}^{\circ}$ 2. Último cuadernillo -"Monedas". Véase figura 6.

17 Las colecciones privadas mencionadas son las de Pascual de Gayangos, Francisco Codera y Zaidín y Aureliano Fernández Guerra mientras que las instituciones son el Museo Arqueológico Nacional de Madrid, la Biblioteca Nacional de Francia (a partir de la obra de H. Lavoix) y las referencias a Ch. M. Fraehn, "Quinque Centuriae Numorum tarios sobre la presencia de monedas de esta clase en diferentes colecciones públicas y privadas, tanto españolas como extranjeras ${ }^{17}$. Da la sensación de tratarse de un borrador de un informe o de un futuro trabajo de Vives que jamás llegó a publicarse.

Vale la pena destacar algunos aspectos de esta breve nota de Antonio Vives; por un lado su mención al estado de máxima fragilidad de los dírhams acuñados en al-Andalus en esta época "Sería curioso un análisis del metal con que se acuñaron estos dírhams, porque ocurre una particularidad: todas las piezas tienen un estado particular de oxidación producido sin duda por vapores de sales sulfurosas produciendo un metal agrio y muy frágil que las orientales han resistido bastante sin romperse pero en cambio las españolas se rompen con la mayor facilidad". Atribuir su fragilidad a su alta pureza es la solución más simple pero no parece la estrictamente correcta habida cuenta de que otros talleres se alcanzan niveles muy similares de pureza y no presentan los mismos problemas. Es indudable que el proceso de fabricación de los cospeles de los dírhams, en este periodo, produce una mineralización intensa del metal y el aumento sustancial de su fragilidad. La alta calidad de estas primeras acuñaciones de alAndalus ha quedado de manifiesto en los diferentes análisis realizados sobre esta serie (Canto e Ibrahim, 2004: 40-41). La verdad es que Vives estaba poniendo el dedo en la llaga en un problema de conservación que afecta a estas monedas y las convierte en objetos muy frágiles.

Otro pasaje interesante es el comentario sobre las monedas de ceca al-Andalus del Museo Arqueológico Nacional de Madrid: "En el $\mathrm{M}^{\mathrm{o}}$. Arqueológico se conservan unos fragmentos de un dírham de 118, siendo este, con un dírham de cobre plateado del año 131 lo único que de esa serie guarda dicha colección (1)" y la nota expli-

Anecdotorum Chalifarum cum Umeijadarum tum Abbasidarum ex variis Museis", Mémoires de l'Académie Impériales des Sciences de Saint-Pétersbourg, vol. IV, 1840, 257-214; J. Hallenberg, Collectio Nummorum Cuficorum, quos aere expressos, addita forum interpretatione sbjunctoque alphabeto cufico, Stockholmo, 1800 y C. J. Tornberg, "Symbolae ad rem numariam muhammedanorum es Museo regio Holmiensi" II, Nova Acta Regiae Societ. Scient. Upsaliensis, vols. I-III, 1855-1858. 
cativa que lo acompaña "(1) El ejemplar que publicamos en el catálogo y en la obra Monedas de las dinastías Arábigo-españolas, $\mathrm{n}^{\circ}$ 24, con fecha de 108 , es muy posterior resultando la fecha ser un error del cuño".

Esta pieza del 108H./727 d.C., ha sido objeto de cierto debate desde hace más de un siglo. La primera mención a esta moneda aparece en 1879 cuando F. Codera había comentado las dudas que le sugería este ejemplar del Museo Arqueológico Nacional de Madrid opinando que se trataba de fecha posterior, posiblemente del 180H./796 d.C., o de esa década (Codera, 1879: 61-2). Pocos años después, en el catálogo de las monedas árabes del Museo Arqueológico Nacional publicado por J. De Dios Rada y Delgado, se incluye este ejemplar como del año 108H./727 d.C., aunque con dudas basadas en la autoridad de Codera (Rada, 1892: 6). Hay que destacar que en la elaboración de este catálogo colaboraron, de forma intensa, tanto Codera como Vives, tal y como señala Rada (Rada, 1892: xii). Quizás de ahí venga la perpetuación del error, la moneda aparece como de la fecha $108 \mathrm{H}$ con la prevención citada...

Un año después Vives la publicó en su obra de 1893, manteniendo su lectura y desde entonces ha sido dada por buena por G. C. Miles quien, al parecer, no la examino directamente aunque expresa los reparos de Codera y Rada sobre la moneda (Vives, 1893: 5, no 24 y 472; Miles, 1950: $119, n^{\circ} .8$ ). Como la obra de A. Vives no llevaba ilustraciones había sido imposible corroborar su afirmación y su autoridad perpetuó su atribución. Desde esta fecha la moneda ha permanecido en el Museo Arqueológico Nacional sin que se hubiera vuelto a publicar ni modificar por la institución.

Sin embargo este ejemplar, como se ha indicado, había levantado sospechas por su paleografía y estilo y hubo que esperar hasta la publicación de las láminas de la obra de Vives, en 1998, para que se pudiera ver una impronta de la moneda y se confirmaran las diferencias paleográficas y de estilo con los dírhams de la conquista. Los editores de las Láminas ya corrigieron esta atribución en el prólogo de la obra mencionada, previa revisión del ejemplar en el Museo Arqueológico Nacional, atribuyéndola al año 198H./813 d.C., por la falta del segundo dígito (Vives, 1998: 7 y 16).
En 2002, M. Klat, en su monografía sobre los dírhams omeyas reformados, menciona esta moneda como "apparently incorrectly described, should be year 208"(Klat, 2002: 68). Estando de acuerdo con Klat en que no es de la fecha propuesta por Vives no coincidimos en su atribución de la época de Abd al-Rahman II, ya que si se consultan las láminas de Vives, se puede comprobar que el estilo de la citada moneda está mucho más cerca del estilo de las batidas a finales del siglo $\mathrm{II}^{\circ}$ de la hégira, que en las del $208 \mathrm{H} . / 823$ d.C., años en los que se produce un marcado descenso en la calidad y cuidado de la acuñación así como en su módulo.

Por fin la última mención a esta moneda, perseverando en el error, se encuentra en la obra de Frochoso sobre el dírham andalusí en época emiral en la que se menciona esta moneda (108.1 MAN.36), citando que "no se ajusta a las características generales de estos años, más bien parece una moneda de los años 180 H. (796/7 d.C.)", sin citar la bibliografía anterior al respecto, y sorprende más que en el catálogo de la misma obra se mantiene el ejemplar cómo del 108H./727 d.C. (Frochoso, 2009: 29 y 1221).

Es de suponer que ahora que sale a la luz el reconocimiento de Antonio Vives sobre su error de lectura (o "error del cuño" como el mismo dice...) esta moneda dejará de ser atribuida, por fín, a la fecha del 108 de la hégira.

Como ya se ha indicado una parte proporcional de este hallazgo parece haberse incorporado a la colección de Guillermo de Osma (quizás más de la mitad del hallazgo, sumando ejemplares de cecas orientales y los de al-Andalus) y de ahí que se hallen depositadas en el Instituto Valencia de Don Juan. El examen de las improntas, tanto de la colección del citado instituto como las procedentes de un estudio iniciado por Antonio Prieto y Vives sobre la moneda islámica permiten identificar algunas monedas como procedentes, casi con toda seguridad, del hallazgo de Carmona (Figs. 1-2) Hay que partir del hecho de que las monedas de este periodo son muy escasas y como Martín Escudero ha estudiado, los hallazgos conocidos son muy pocos y menos en las fechas en las que se forma esta colección.

En ellas suele aparece la letra $\mathrm{O}$, indicativo de Osma, acreditando su pertenencia a la colección de Guillermo de Osma y dadas las coincidencias 
de fechas y de número de inventario dentro de la colección, al igual que ocurre con los ejemplares de Al-Andalus, su procedencia debe ser el tesoro de Carmona. En el caso de la ceca de Ifriqiya, las notas de Vives mencionan cuatro ejemplares de los años 103,105 y 114H. /721, 723 y 732 d.C. y en las láminas depositadas en Instituto Valencia de Don Juan se encuentran improntas de ejemplares de esta ceca y de los años 105 y 114H./723 y 732 d.C.

Es verdad que existe una discrepancia en este documento ya que se habla de monedas de alAndalus en dos momentos diferentes: en el listado sobre todo el conjunto, al comienzo del texto, se registran monedas de los años 111 (1), 114 (2), 115, 116, 117 y 135 (3). Sin embargo, en páginas posteriores Vives establece una comparación entre las monedas de ceca al-Andalus depositadas en las principales colecciones españolas y extranjeras y su comparación con el hallazgo de Carmona sin que podamos asegurar que se trate de las monedas ingresadas en la colección de Osma. En esta segunda relación se mencionan monedas de los años 105, 108, 111 (3), 114 (2), 115, 116 (3), 117, 129 (3), y 135 (6).

No tenemos una explicación clara para esta divergencia. Parece evidente que un caso podría referirse a las monedas presentes en el hallazgo y la diferencia podría atribuirse a los ejemplares que son adquiridos por Osma mientras que en otras monedas pudiera tratarse de una diferente interpretación del material; así ocurriría en las monedas del año 135 que, en un lado aparecen citados seis ejemplares y en la otra relación, tres monedas y tres fragmentos que, evidentemente pueden corresponder a seis monedas distintas, a efectos cuantitativos.

De los ejemplares de ceca al-Andalus, que puedan proceder del hallazgo de Carmona la serie de improntas de la colección numismática del Instituto Valencia de Don Juan recoge dos ejemplares del año 111 y de los años 114, 115, 117 y 135. Vives anota tres ejemplares del 111H./729 d.C., y añade el comentario "En un ejemplar del 111 se presenta un modelo o variación de gran elegancia consistente en que además de un gran esmero en el trazado de las leyendas, la orla de la $1^{\text {a }}$ Área está separada de la inscripción del campo por un círculo, que le da un aspecto elegantísimo". Dos improntas se corresponden con mone- das de este año y una de ellas (Fig. 1) se ajusta al comentario de Vives (Klat, 2002:124b) mientras que la segunda corresponde al modelo de orla marginal de anverso circular (Klat, 2002:124c). Las restantes improntas corresponden a una moneda de cada año, 114H./732 d.C. (Klat, 2002: 127); 115H./ 733 d.C. (Klat, 2002: 128); 117H./ 735d.C. (Klat, 2020:130) y una impronta de los rarísimos ejemplares del año 135H./752 d.C. (Canto e Ibrahim, 2004:18-19) ausente en los repertorios de Vives, Miles o Klat.

Es posible que alguna moneda de este conjunto terminara en otra colección pública o privada como la colección del Museo Arqueológico Nacional de Madrid (Canto e Ibrahim, 2004: 24 y 149; Martín Escudero, 2005: 50).

En el análisis de la colección Vives que ha realizado Paula Grañeda, informa que, tras el ingreso de gran parte de su colección, en 1910 llevan más monedas pero que "si bien en ocasiones se ha publicado que A. Vives donó otros ejemplares hispano-musulmanes en 1910, el expediente de la "Donación que hace don Antonio Vives, de 56 dírhams y dos fragmentos y dos dírhams de los años 116 y 135 de la Hégira" aclara que Vives entregó estas piezas, en 12 de junio y 10 de agosto de 1910 , autorizado por un donante cuyo nombre se reservó y al que "no se dieron las gracias porque así lo indicó" (Grañeda, 2009: 774, Exp. MAN 1910/42). Estas monedas, proceden del hallazgo de Carmona y serían donadas, a través de Vives, casi con toda seguridad por su propietario Guillermo de Osma (Fig. 2). Al analizar dicho expediente se observa que se donarían entre ambas fechas 55 dírhams y dos fragmentos de cecas orientales más 3 dírhams de ceca alAndalus, acuñados en los años 116, 129 y 135H./734, 746 y 752 d.C.

Consta además, como ya indicamos al inicio, que Osma dona directamente al Museo Británico dos dírhams, uno de ceca al-Andalus año 129H./ 7468 d.C. y el otro emitido en Wasit en el año 108H./726 d.C.

Y, según Maier, Jorge Bonsor adquirió 33 dírhams que acabaron integrándose en la colección Osma, según Maier, aunque no hemos podido comprobar este hecho (Maier, 2004: 81).

Con estas últimas informaciones parece que queda recogida toda la documentación y cerrada la información que sobre este hallazgo, quizás 
uno de los más documentados que de la moneda andalusí de primera época existe y que permite recomponer, identificar en parte y ubicar los materiales preservados.

\section{Bibliografía}

ASÍN PALACIOS, M. (1907): "Noticia", Cultura Española, noviembre, 4, 971-972.

ASSEMANI, José Simón (1787): Museo cufico Naniano. Pavoda.

BARCELÓ, M. (1997): “¿Monedas lejanas? Nuevos indicios sobre la producción de monedas y la práctica administrativa fiscal durante el Califato omeya tardío", El sol que salió por Occidente. Estudios sobre el estado Omeya en Al-Andalus. Jaén, 73-83.

CANTO GARCÍA, A. IBRAHIM, T. IBN HAFIZ (2004): Moneda andalusí. La colección del Museo Casa de la Moneda, Madrid.

CANTO GARCÍA, A. y MARTÍN ESCUDERO, F. (2000): "El hallazgo de Belalcázar (Córdoba): nuevas aportaciones", Qurtuba, 5. Córdoba, 2740.

CANTO GARCÍA, A. y MARTÍN ESCUDERO, F. (2007): "Los hallazgos ausentes", en Baena Alcántara, Ma. D. y Canto García, A., Maskukat. Tesoros de Monedas Andalusíes en el Museo Arqueológico de Córdoba. Córdoba, 75-80.

CANTO GARCÍA, A.; MARTÍN ESCUDERO, F. y VICO MONTEOLIVA, J. (2002): Monedas Visigodas. Catálogo del Gabinete de Antigüedades de la Real Academia de la Historia. Madrid.

CODERA Y ZAIDÍN, F. (1879): Tratado de numismática arábigo-española, Madrid.

FROCHOSO SÁNCHEZ, R. (2009): El dirham andalusí en el emirato de Córdoba, Madrid.

GRAÑEDA MIÑÓN, P.: "Las monedas emirales y califales de la colección Vives", XIII Congreso Nacional de Numismática. Cádiz, 22-24 octubre de 2007. Cádiz, 2009. 771-797.

IBRAHIM, T. (2003: "La colección de improntas del Instituto Valencia de Don Juan", III Jarique de Numismática Hispano-Árabe, Madrid, 313-324

KLAT, M.G. (2002): Catalogue of the Post-Reform Dirham. The Umayyad Dinasty, Londres.
LAVOIX, H. (1891): Catalogue des monnaies musulmanes de la Bibliothèque Nationale, II: Espagne et Afrique. París.

MAIER ALLENDE, J. (1998): "Sobre los primeros estudios histórico-arqueológicos de la Carmona medieval", Archivo hispalense. Revista histórica, literaria y artística, XXX, $\mathrm{n}^{\circ}$ 243-245. Sevilla, 79-93.

MAIER ALLENDE, J. (1999): Epistolario de Jorge Bonsor (1886-1930). Real Academia de la Historia. Madrid.

MAIER ALLENDE, J. (2004): "El hallazgo de un tesoro omeya en el cortijo de Santa Clara (Carmona): correspondencia entre Juan Fernández López y Guillermo de Osma y Scull”, Estela, p. 78-84.

MARTÍN ESCUDERO, F. (2001):"El hallazgo omeya de Baena: un tesoro olvidado", Actas IV Jarique de Numismática Andalusí. Canto, A. y Salvatierra. V. (eds.). Jaén, 81-94.

MARTÍN ESCUDERO, F. (2003): "Sobre el hallazgo de dinares del Hospital Militar de Zaragoza (1858)", Actas XI Congreso Nacional de Numismática. Zaragoza, 257-268.

MARTÍN ESCUDERO, F. (2005a): El tesoro de Baena, Madrid.

MARTÍN ESCUDERO, F. (2005b): "Hallazgos de dirhames omeyas: estudio e interpretación", Actas XIII Congreso Internacional de Numismática. Madrid, 1615-1623.

MARTÍN ESCUDERO, F. (2011): Las monedas de alAndalus y el estudio de sus monedas. De actividad ilustrada a disciplina científica. Madrid.

MILES, G.C. (1950): The Coinage of the Umayyads of Spain, Nueva York.

RADA Y DELGADO, J de D. (1892): Catálogo de monedas arábigas españolas que se conservan en el Museo Arqueológico Nacional, Madrid.

RODRÍGUEZ CASANOVA, I. (2009): "El tesoro de Manzaneda (Oviedo): los ilustrados asturianos y la Numismática", Documenta \& Instrumenta, 7. Madrid, 149-159

VIVES ESCUDERO, A. (1893): Monedas de las dinastías arábigo-españolas, Madrid.

VIVES ESCUDERO, A. (1998): Monedas de las dinastías arábigo-españolas. Láminas, ed. T. Ibrahim y A. Canto García, Madrid.

WALKER, J. (1956): A Catalogue of the ArabByzantine and Post-Reform Umaiyad Coins, Londres. 


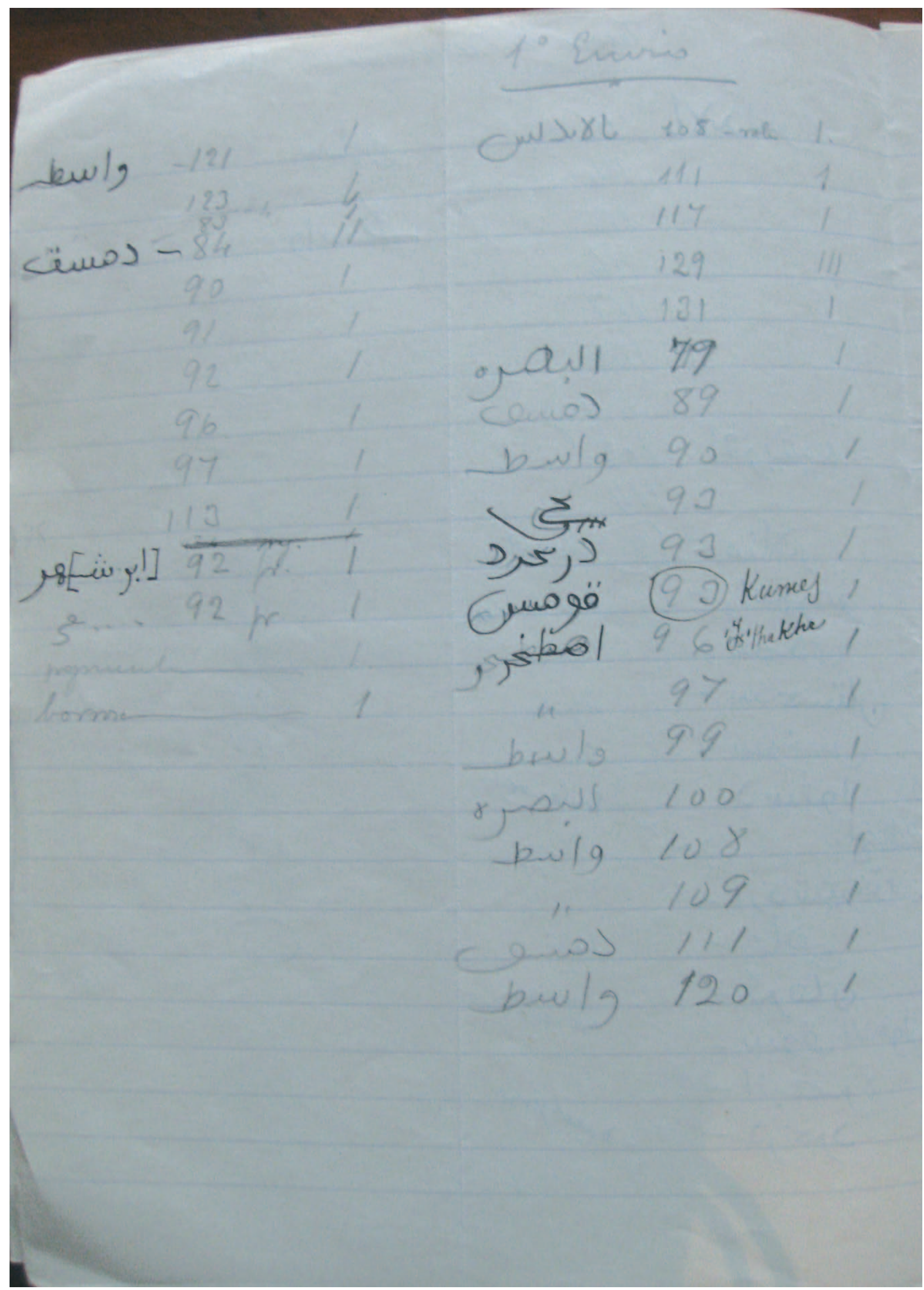

Figura 3.- Listado 1er envío de monedas (IVDJ). 


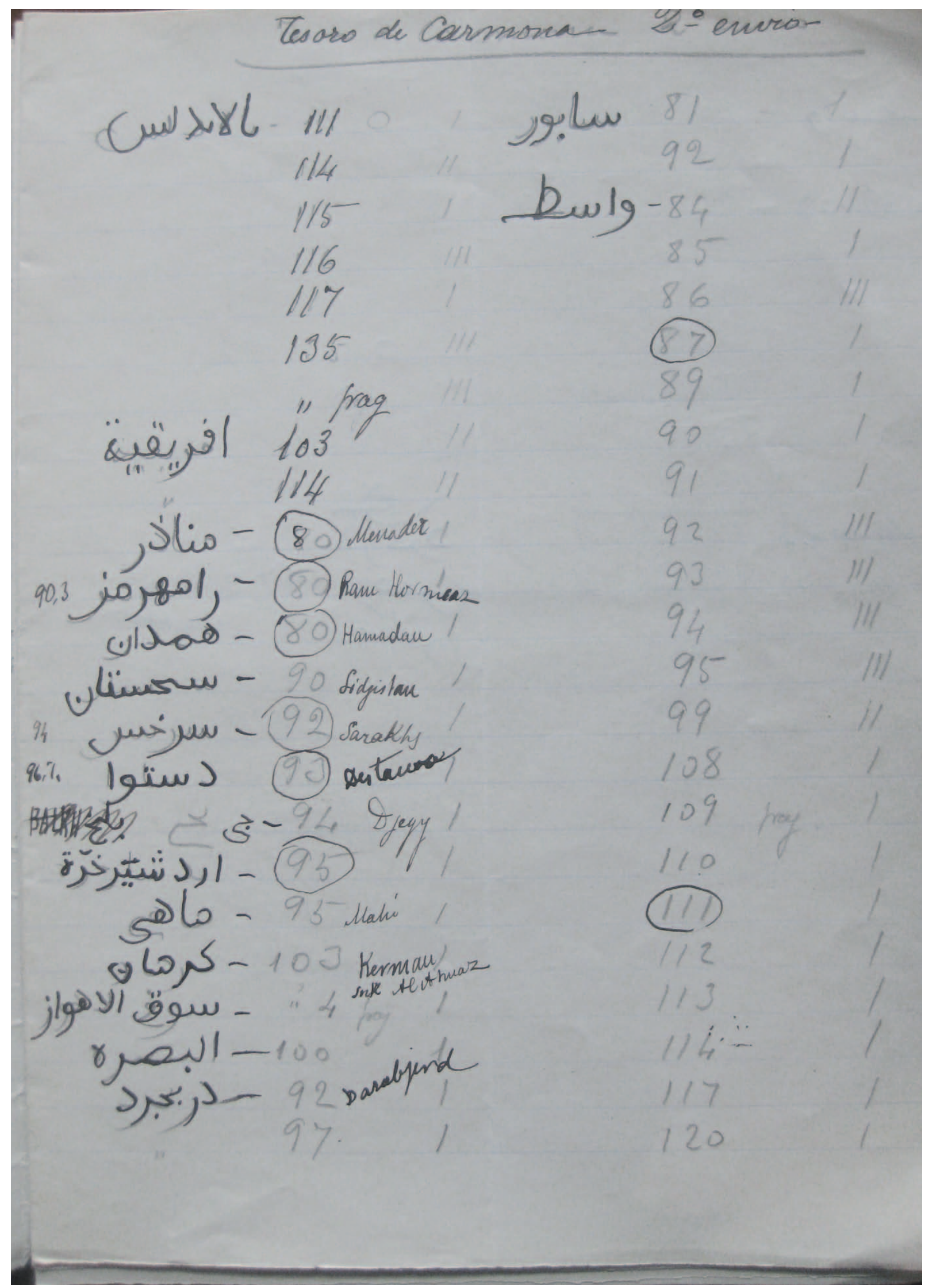

Figura 4.- Listado $2^{\circ}$ envío de monedas (IVDJ). 


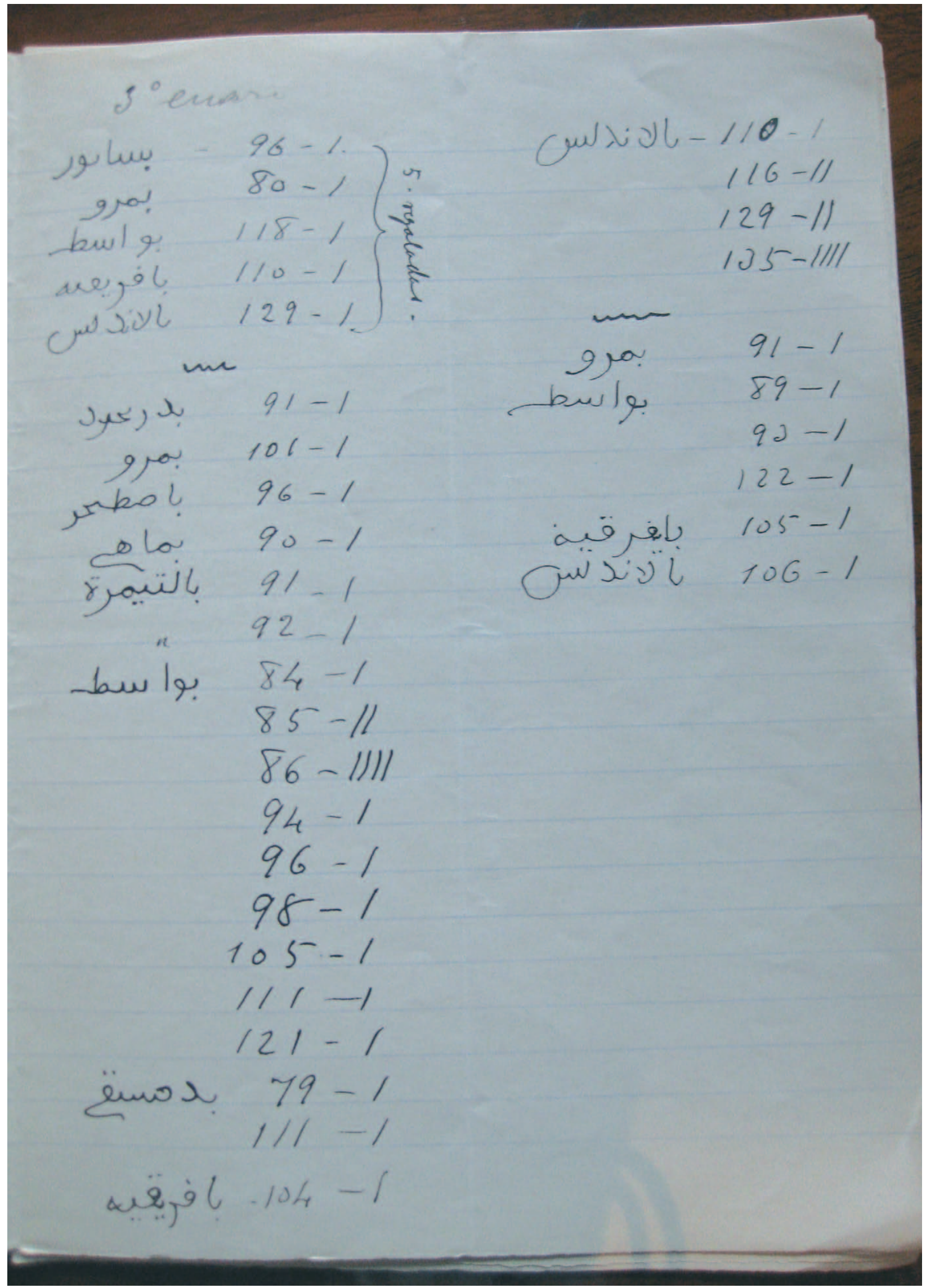

Figura 5.- Listado 3er envío de monedas (IVDJ). 
748

Alberto J. Canto García - Fátima Martín Escudero

CUPAUAM 37-38, 2011-12

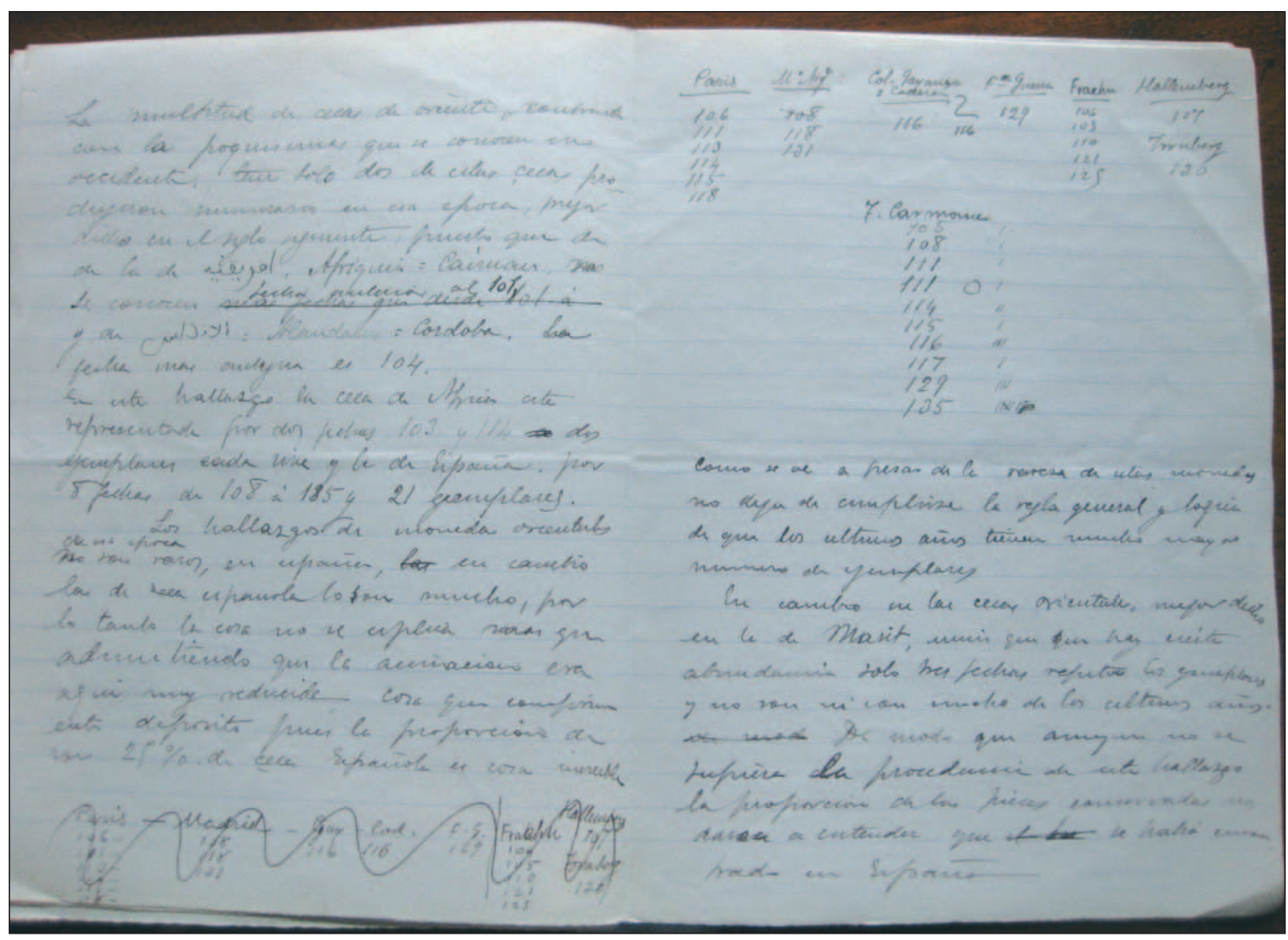

Figura 6.- Informe de Vives acerca del hallazgo de Santa Clara (IVDJ).

$10^{\circ}$ In 12 de Imio An Anteliver entorizado por otra proriona cuyo nombre re verevva entrage en la sección de Numimation dos chirhem de los años 116 el uno $y$ ele 135 et otro 2. In 10 de Agorto el miniso seños y en la nusma tolor ele cecas ovienteler exedpto uns gue

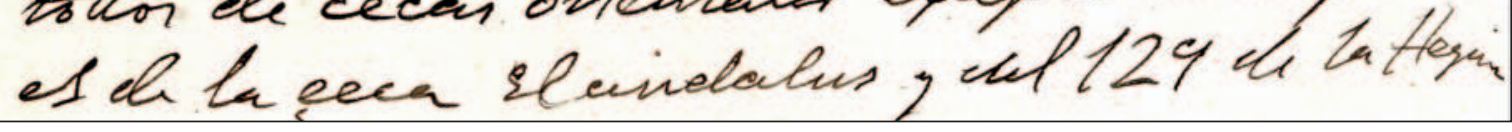

Figura 7.- Expediente 1910/42 del MAN relativo a la donación "anónima” de dírhams. 